\title{
CONFLICTIVIDAD Y DESPLAZAMIENTO AMBIENTAL: ELEMENTOS JURÍDICO-POLÍTICOS DE JUSTICIA AMBIENTAL Y REPARACIÓN A SOCIEDADES TRADICIONALES ${ }^{1}$
}

\author{
Gregorio Mesa CuAdros \\ Profesor asociado y vicedecano académico de la Facultad de Derecho, Ciencias \\ Politicas y Sociales de la Universidad Nacional de Colombia \\ gmesac@unal.edu.co
}

\begin{abstract}
"Uno no puede vivir en un constante desarraigo y abandono. El ser humano tiene necesidad espiritual de raíces. Los miembros de comunidades tradicionales valoran particularmente sus tierras, que consideran que a ellos pertenecen, así como, al revés, ellos ‘pertenecen’ a sus tierras”.
\end{abstract}

Voto razonado del juez Antônio Augusto Cançado Trindade, párrafo 13, Sentencia de 6 de febrero de 2006, caso de la comunidad indígena Yakye Axa contra Paraguay.

Recibido: 14 de octubre de 2014 / Aceptado: 11 de marzo de 2015

RESUMEN: El proceso de desarrollo agenciado por el modelo hegemónico de apropiación de la naturaleza recurre a proyectos y megaproyectos de extracción que, en lo sustantivo, generan desplazamiento ambiental de pueblos, sociedades y comunidades tradicionales rurales y agrarias que habitan ancestralmente bosques y territorios colectivos. En este escrito presentamos algunos de los momentos más significativos del desplazamiento ambiental resultado de las actividades humanas que generan proyectos, obras o actividades de empresas alrededor del mundo y que, en las últimas décadas, usan sin límite o control los bosques naturales, el aire, los suelos, el subsuelo y demás elementos del ambiente.

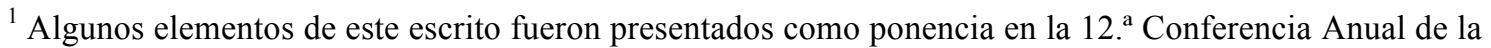
Academia de Derecho Ambiental de la Unión Internacional para la Conservación de la Naturaleza (UICN). en el Centro de Estudios de Derecho Ambiental de Tarragona (CEDAT), Universitat Rovira i Virgili, Tarragona, Cataluña, entre el 30 de junio y el 5 de julio de 2014.
} 
Paradójicamente, las sociedades tradicionales, que han conservado los bosques, el agua y los suelos por muchos años, son violentadas en sus derechos y tienen que huir o desplazarse de sus territorios tradicionales por un modelo de desarrollo inadecuado basado en huellas ambientales y energéticas insostenibles. Este modelo ha establecido que todo puede ser apropiado en la naturaleza y que los límites ambientales podrían ir en contra del desarrollo y los derechos de las personas, desconociendo la cruda realidad del deterioro ambiental que afecta a los más vulnerables, que terminan desplazados forzadamente de sus tierras y se convierten en "migrantes climáticos".

Nuestra reflexión se desarrolla en dos momentos: el primero establece las formas de apropiación de la naturaleza que llevan a la degradación y contaminación de elementos ambientales clave para la vida presente y futura y sus consecuencias ambientales (ecosistémicas y culturales) sobre las sociedades tradicionales que habitan bosques naturales; el segundo recupera el papel de estas sociedades tradicionales en la conservación ambiental y propone una visión alternativa desde el Derecho ambiental para el reconocimiento y la compensación como sujetos colectivos vitales en la resolución de los conflictos y problemas globales actuales y en la concreción de una idea de dignidad y justicia ambiental.

RESUM: El procés de desenvolupament promogut pel model hegemònic d'apropiació de la naturalesa recorre a projectes i megaprojectes d'extracció que, de manera substantiva, generen desplaçament ambiental de pobles, societats i comunitats tradicionals rurals i agràries que habiten ancestralment boscos i territoris col·lectius. En aquest escrit, presentem alguns dels moments més significatius del desplaçament ambiental resultat de les activitats humanes que generen projectes, obres o activitats d'empreses arreu del món i que, en les darreres dècades, utilitzen sense límit o control els boscos naturals, l'aire, els sols, el subsòl i la resta d'elements del medi ambient.

Paradoxalment, les societats tradicionals, que han conservat els boscos, l'aigua i els sols durant molts anys, són violentades en els seus drets i tenen que fugir o desplaçar-se des dels seus territoris provisionals per un model de desenvolupament inadequat, basat en empremtes ambientals i energètiques insostenibles. Aquest model ha establer que tot pot ser apropiat en la naturalesa i que els límits ambientals podrien anar contra el desenvolupament i els drets de les persones, tot desconeixent la crua realitat del 
deteriorament ambiental, que afecta als més vulnerables, que acaben desplaçats forçadament de les seves terres i es converteixen en "migrants climàtics".

La nostra reflexió es desenvolupa en dos moments: el primer estableix les formes d'apropiació de la naturalesa que duen a la degradació i contaminació d'elements ambientals clau per a la vida present $\mathrm{i}$ futura, $\mathrm{i}$ les seves conseqüències ambientals (ecosistèmiques i culturals) sobre les societats tradicionals que habiten boscos naturals; el segon recupera el paper d'aquestes societats tradicionals en la conservació ambiental i proposa una visió alternativa des del dret ambiental per al reconeixement i compensació, com a subjectes col·lectius vitals en la resolució dels conflictes i problemes actuals, i en la concreció d'una idea de dignitat i justícia ambiental.

ABSTRACT: The development process built up on the hegemonic model of appropriation of nature resorts to mega projects of extraction that generate environmental displacement of peoples, traditional societies, and agricultural and rural communities that inhabit forests and ancestral collective territories. In this paper we present some of the most significant moments of the environmental displacement that results of human activities generated by projects or activities of companies around the world, that in recent decades, have used without limits or monitoring the natural forests, air, soil, subsoil and other environmental elements.

Paradoxically, the rights of people who have preserved the forest, water and soil for many years, are violated. Besides they have been forced to flee or move from their traditional territories by an unsustainable model based on significant environmental and energy footprints. Within this model everything can be appropriate in nature and the environmental limits could oppose the development and rights of individuals. However this position ignores the harsh reality of environmental degradation that affects the most vulnerable population that, at the end, is displaced from their land and became into "climate migrants".

Our reflection is developed in two stages. The first shows the ways of appropriation of nature that lead to degradation and contamination of the environmental elements that are essential to the present and future life and specifies the environmental consequences (ecosystemic and cultural) on the traditional societies who live into the natural forests. The second analyses the role of these traditional societies in environmental conservation 
and proposes an alternative view of environmental Law aiming to their recognition and compensation as collective subjects, who are vital to resolve the conflicts and current global issues and the realization of an idea dignity and environmental justice.

PALABRAS CLAVE: Conflictos ambientales - Sociedades tradicionales - Cambio climático — Justicia ambiental.

PARAULES CLAU: Conflictes ambientals - Societats tradicionals - Canvi climàtic — Justícia ambiental.

KEYWORDS: Environmental conflicts - Traditional societies - Climate change Environmental justice.

SUMARIO: I. Introducción. II. Apropiación de la naturaleza, conflictos y desplazamientos ambientales. III. Justicia ambiental: elementos jurídico-políticos para reparación integral de sociedades tradicionales desplazadas y víctimas de conflictos ambientales. IV. A manera de conclusiones. V. Bibliografía.

\section{INTRODUCCIÓN}

El "antropoceno"2 es la era actual en la cual el cambio climático originado por causas antropogénicas precisa debates jurídico-políticos pertinentes para encontrar caminos a la resolución de las nuevas formas de indignidad humana que, sumadas a las formas anteriores de acción humana injusta, desconocen los derechos de los humanos y no humanos presentes y futuros.

Los seres humanos, desde los comienzos de la cultura, nos hemos apropiado de la naturaleza para satisfacer necesidades básicas y, posteriormente, para satisfacer además deseos y preferencias humanos. En los últimos tiempos, la naturaleza se usa mayoritariamente en deseos y preferencias de unos pocos humanos, ya que, tal como afirma Naciones Unidas, hoy más del 90\% de los recursos del planeta son apropiados por menos del $10 \%$ de sus habitantes.

\footnotetext{
${ }^{2}$ Este es un término acuñado en el año 2000 por Paul Crutzen, premio Nobel de Química, al considerar la decisiva influencia de los seres humanos sobre la naturaleza, que cambia de manera radical la forma como esta funciona.
} 
Hoy el proceso de desarrollo autoriza la apropiación de la naturaleza mediante proyectos y megaproyectos de extracción que generan desplazamiento ambiental de sociedades tradicionales rurales y agrarias que habitan ancestralmente territorios colectivos.

El desplazamiento ambiental es el resultado de las actividades humanas que generan proyectos, obras o actividades de empresas privadas y públicas alrededor del mundo, las cuales, en las últimas décadas, usan sin límite ni control los bosques naturales, el aire, los suelos o el subsuelo, la fauna y demás elementos del ambiente, generando maldesarrollo y afectando a quienes han conservado los bosques por centurias o milenios y resultan violentados en sus derechos ambientales y tienen que huir o desplazarse de sus territorios tradicionales por un modelo de desarrollo basado en el crecimiento ilimitado.

Afirmar que la principal causa de los conflictos ambientales está asociada a acciones humanas no dice mucho y no precisa quiénes son los principales humanos responsables y sus empresas; por ello, la comunidad internacional y los Estados industrializados, así como la academia, deberían dar cuenta de la responsabilidad ambiental específica por las consecuencias e impactos ambientales negativos que las conductas de esos seres humanos y empresas dejan sobre el ambiente y las afectaciones específicas a pueblos y sociedades tradicionales colombianos y latinoamericanos, que por su vulnerabilidad histórica deben soportar las consecuencias de acciones no queridas y agenciadas usualmente lejos de sus territorios.

\section{APROPIACIÓN DE LA NATURALEZA, CONFLICTOS Y DESPLAZAMIENTOS AMBIENTALES}

Es un hecho que los seres humanos como individuos y como culturas requerimos la naturaleza y sus elementos para vivir. Desde que somos humanos, venimos usando la naturaleza, y la cultura define cómo acceder a ella, estableciendo reglas, normas y 
conductas permitidas o prohibidas, las cuales configuran lo que podemos denominar genéricamente derecho ambiental ${ }^{3}$.

Habiendo usado históricamente la naturaleza, las primeras formas lo hicieron de una manera poco agresiva con el ambiente, pero el surgimiento de imperios antiguos implicó la apropiación desmedida de algunos elementos. En este escrito queremos destacar algunas de las formas de apropiación de la naturaleza en los tiempos modernos ${ }^{4}$ (en los últimos cinco siglos), pues evidencian una forma "especial" de acceso a la naturaleza o al ambiente que trasciende fronteras físicas y artificiales de sociedades y Estados y lo hacen desde particulares fórmulas de conceptualizar y fundamentar tal apropiación privatística de los elementos de la naturaleza a favor de unos pocos y en contra del interés general o común.

Una de las acciones más conocidas de apropiación de la naturaleza, que no es de uno, se puede encontrar en la historia ambiental moderna con ocasión de la conquista del Nuevo Mundo por los europeos y sus potencias constituidas en Estado-nación, quienes formulan la apropiación de las nuevas tierras (de propiedad de pueblos y comunidades precolombinos), de sus recursos y de sus habitantes a favor del conquistador.

Desde un siglo antes, los enclosures - el proceso de despojar de las tierras comunales a campesinos europeos occidentales- continúan siendo constituidas por nuevos terratenientes, lo que contribuye al surgimiento de una nueva clase propietaria a finales del período feudal en la Europa occidental de los siglos XIV y XV. A finales del siglo XVII, Locke en el Segundo Tratado del gobierno civil formula la idea de apropiación ilimitada de tierras que no son usadas o apropiadas debidamente como lo debe hacer un civilizado; por ello, el conquistador inglés puede apropiarse de las tierras indígenas de

\footnotetext{
${ }^{3}$ La historia del Derecho ambiental no es más que la historia de la apropiación de la naturaleza por los seres humanos y se basa en autorizar o prohibir tal apropiación.

${ }^{4}$ Las tragedias ambientales no son exclusivas de la modernidad ni del sistema capitalista, ya que a lo largo del siglo XX la depredación y la contaminación también fueron significativas en el sistema soviético (como en los casos de Chernóbil y la destrucción del mar de Aral). Asimismo, algunas sociedades premodernas asiáticas, europeas y precolombinas sucumbieron y desaparecieron o se extinguieron al desarrollar una estrategia de relación con la naturaleza y los elementos ambientales basada en un uso intensivo más allá de sus límites, cuyos ejemplos paradigmáticos los encontramos en el mundo maya, la última fase del Imperio romano o la fase de extinción de árboles en la isla de Pascua a la llegada del europeo en el siglo XVIII, entre otros. Para un debate en mayor profundidad, puede verse la teoría de Harris (1994) sobre el materialismo cultural y la crítica de Polanyi (1944) a la gran transformación de la naturaleza desarrollada por el capitalismo.
} 
Norteamérica o de la India, pues "vive mejor el más miserable de los proletarios ingleses que el más grande de los reyes indígenas de Norteamérica",5.

Los revolucionarios franceses concretan el deseo burgués de la propiedad individual en el Código Civil de 1804 al eliminar cualquier forma "premoderna" de propiedad colectiva o comunitaria de uso y acceso a bienes comunes bajo el argumento de oponerse a la libertad de intercambiar propiedad. En el Congreso de Berlín de 1885, se consolida la teoría de distribución de África entre todas aquellas metrópolis europeas con capacidad de apropiarse y manejar las nuevas relaciones de poder imperial basadas en el carácter civilizatorio del europeo frente al negro, que ha nacido para ser esclavo, y en la libertad de comerciar y vender la tierra y demás bienes de la naturaleza.

Las guerras mundiales del siglo XX implicaron un uso desmedido de la naturaleza y en la década de 1960 aparece la "revolución verde", que propone producir alimentos mediante el monocultivo y el uso intensivo de agroquímicos. En 1968 Garret Hardin presenta la idea de privatizar la naturaleza como la única manera de resolver la nueva "tragedia de los comunes" $"$ y por la misma época aparece y se consolida jurídicamente el "patrimonio común de la humanidad" desde una nueva retórica de bienes comunes que, en la práctica, significan la protección para que estados y empresas se apropien privadamente de esos bienes por su poder material militar, tecnológico o financiero, donde patentes sobre plantas, animales, "recursos genéticos", transgénicos y clonación humana son la nueva forma de apropiación de la naturaleza, sumada a lo expresado en 1991 en el Memorando tóxico de Lawrence Summers ${ }^{7}$, que promueve la exportación de la contaminación producida por los países industriales a los países de "coste mínimo", que serán, según él, "los países con salarios más bajos”, es decir, los países pobres hoy llenos de maquilas, joint ventures, extractivismo y commodities.

\footnotetext{
${ }^{5}$ La teoría de Locke de la apropiación ilimitada se da a partir de precisar que los humanos nos podemos apropiar de la naturaleza o de sus elementos cuando invertimos energía o trabajo, siempre y cuando se conserve un límite a la apropiación (dejar bueno y suficiente para los demás); pero la regla se rompe cuando aparece el dinero, pues este no se pudre y, además, es abundante y por ello se puede acumular. Si aplicamos esta regla a las tierras de Norteamérica, sucede lo mismo, hay mucha tierra y, además, hay seres que no saben usarla, la desaprovechan, y, por ello, un inglés puede apropiarse ilimitadamente de esas tierras, sin mayor vergüenza para el ser humano racional de comienzos de la Modernidad.

${ }^{6}$ HARDIN, Garret, “Tragedy of the Commons", Science, vol. 162, núm. 3859, 13 de diciembre de 1968, pp. 1243-1248.

${ }^{7}$ SUMMERS, Lawrence, "Memorando", En: George, S. y Sabelli, F., La religión del crédito. El Banco Mundial y su imperio secular, Intermón, Barcelona, 1996, pp. 127-143.
} 
A finales del siglo XX y comienzos del actual, las nuevas figuras de apropiación del ambiente o naturaleza y de uno o varios de sus elementos o componentes, que la literatura convencional de la modernidad denomina recursos naturales, pasa por la apropiación de los conocimientos tradicionales, el agua, las semillas, los alimentos, las tierras para producirlos, los minerales e incluso áreas de especial importancia ecosistémica como los páramos, los humedales, los bosques andinos o las selvas y llanuras tropicales, que el capital decide cuándo y cómo pueden ser apropiados privadamente desde la práctica de "teñir de verde" las actividades de las empresas y los Estados, que las mismas cumbres globales sobre ambiente y desarrollo promueven desde conceptos como ecodesarrollo, desarrollo sostenible o economía verde.

Este último concepto viene complementado con la socialización a todos los sujetos de los pasivos ambientales, la privatización de la institucionalidad ambiental estatal, el desarrollo de los conceptos privatísticos de la autodenominada "responsabilidad social empresarial", las gabelas a la inversión extranjera, el acaparamiento de tierras, semillas y alimentos, los filántropos evasores, la bancarización forzada de todos los ciudadanos en la que todos tributen (incluso los más pobres), el canje injusto de deuda por naturaleza $\mathrm{y}$, especialmente, los mercados de carbono (que algunos teóricos conceptualizan como mercados de derechos de contaminación) y las estrategias de "adaptación" al cambio climático de quienes sufren las consecuencias de las acciones inadecuadas de huellas y deudas ambientales insostenibles de una pequeña parte de la población del globo basada en sobreconsumos exosomáticos para satisfacer solo deseos y preferencias humanos.

Por lo anterior, consideramos que los conceptos de cambio climático (la causa y consecuencia) y economía verde (el remedio) son la fórmula que las teorías del derecho, los (no) derechos y la (in)justicia liberal formulan para su quehacer como nueva fórmula para la apropiación de la "naturaleza toda" que está en venta y convertida en mercancía.

Todas las anteriores formas de apropiarse de manera injusta del ambiente en general o de alguno o varios de sus elementos en particular están basadas en huellas ambientales insostenibles que fundamentan la apropiación generalizada del ambiente y la naturaleza o ecosfera y originan destrucción y contaminación ambientales y, con ello, desplazados ambientales. 
Por otro lado, el concepto de huella ambiental ${ }^{8}$ está asociado a la cantidad de ambiente o naturaleza que los seres humanos (ya sea como culturas o como individuos) usamos en nuestras vidas tanto en consumos endosomáticos (para satisfacer necesidades básicas) como exosomáticos (para satisfacer meros deseos y preferencias humanos), y, por ello, son los consumos - y especialmente los sobreconsumos- de una parte de la población humana los generadores de la sobreextracción de los elementos del ambiente (recursos naturales), que ocasiona su erosión (reducción, disminución, agotamiento y extinción) o contaminación (es decir, incorporación de sustancias nocivas para el ambiente y los elementos ambientales) más allá del límite permisible para que el ambiente se regenere por sí mismo.

Se reconoce que los consumos exosomáticos cada vez se incrementan para una pequeña parte de la población del mundo y cada vez más millones de seres humanos no pueden satisfacer siquiera sus necesidades básicas; asimismo, si el nivel de consumo de los países industrializados y de los sobreconsumidores de los países en desarrollo se generalizara, ¿cuántos planetas se necesitarían? Las consecuencias de dicho consumo no sostenible ni universalizable, si se valoran bajo conceptos alternativos a la crematística o economía convencional, indicarían que son mucho mayores que las deudas externas de los países afectados.

Por todo lo anterior, el desplazamiento ambiental usualmente ha sido teorizado como producto de las acciones de la naturaleza, pero en este escrito enfatizamos que el desplazamiento ambiental en sentido estricto tiene una doble causalidad, la humana y la natural, y, para los efectos de nuestro debate, analizaremos los problemas asociados al desplazamiento ambiental producto de la conducta humana y sus consecuencias jurídico-políticas, sociales y ambientales, que tienen que ver, en particular, con la responsabilidad de seres y colectivos humanos, las empresas y el Estado?.

En efecto, en diversas regiones del mundo poblaciones y sociedades tradicionales están siendo afectadas o sufriendo los efectos de la conflictividad ambiental, incluida la del cambio climático, que fuerzan a individuos y poblaciones a abandonar sus territorios

\footnotetext{
${ }^{8}$ Que en la literatura se enuncia como 'huella ecológica', tal como se expresa en WACKERNAGEL, Mathis y REES, William, Nuestra huella ecológica. Reduciendo el impacto humano sobre la tierra, Instituto de Ecología Política - LOM eds., Santiago de Chile, 2001.

${ }^{9}$ Todos los que participaron en la generación de riesgos, daños e impactos ambientales negativos deben concurrir como responsables por tales conductas, pues son deudores individuales o solidarios por las conductas jurídicamente reprochables.
} 
ante los resultados del incremento de los desastres naturales, la mayoría de ellos ocasionados a su vez por acciones humanas.

Consideramos "desplazados ambientales" a las personas, grupos, colectivos o sociedades y pueblos que, presionados por conflictos y problemas ambientales de diversa índole, resultan afectados directa o indirectamente, así como sus territorios, viviendas y formas de vida, por lo que se ven obligados a trasladarse a otro lugar en busca de mejores condiciones de vida.

Las causas del desplazamiento ambiental son naturales y antrópicas o generadas directa o indirectamente por el ser humano, pero las causas naturales hoy son menos frecuentes y graves y la mayoría de las que se dan hoy como naturales se agravan justamente por la relación estrecha con causas culturales asociadas a la presión indebida e inadecuada sobre ecosistemas y territorios de un modelo de desarrollo extractivista, depredador, contaminador e injusto que genera víctimas entre los más empobrecidos, los cuales usualmente viven en los territorios con mayor riqueza en diversidad biológica y cultural.

Puede evidenciarse desde la historia de la apropiación de la naturaleza o el ambiente, que muestra, a comienzos del siglo XXI y, en particular, en el discurso de normas y políticas de acceso al ambiente y sus elementos incluyendo la adaptación al cambio climático, la nueva fórmula de despojo de los pocos bienes comunes administrados por sociedades tradicionales, que son las nuevas víctimas de hechos de terceros que las fuerzan a desplazarse de sus bosques y demás tierras comunales para que empresas nacionales y transnacionales, cubiertas del velo de la supuesta "legalidad", exploren, extraigan, depreden y contaminen los bienes que contienen las condiciones materiales de posibilidad de concretar la sostenibilidad global, reciclando el $\mathrm{CO}_{2}$ y los demás gases contaminantes.

Esta historia de la apropiación inadecuada no es nueva ni reciente, puesto que la historia del derecho ambiental no es más que la historia de la apropiación de la naturaleza por unos - que usualmente no son sus dueños o propietarios - a costa de sus verdaderos propietarios - que van desde las sociedades tradicionales en la versión de la propiedad sobre bienes específicos hasta todos si seguimos la teoría del patrimonio común de la humanidad $^{10}$ -

\footnotetext{
${ }^{10}$ Se considera a los ecologistas como los integrantes de una corriente muy importante del movimiento a favor de la naturaleza que predican la protección de los ecosistemas, aunque sin defender directamente al
} 
De lo anterior, jurídicamente hablando nos preguntamos, ¿quién es el propietario de los territorios tradicionales y los bosques?, ¿los Estados, las comunidades o las empresas? Son múltiples las teorías al respecto; entre ellas, la ausencia de propiedad sobre los territorios y bosques o el libre acceso sobre estos, los territorios como patrimonio común de la humanidad, el fideicomiso ambiental sobre estos, la propiedad estatal, la propiedad privada individual, la propiedad colectiva o los bienes comunes ${ }^{11}$.

Cada una de estas tipologías indica quién o quiénes son los propietarios y excluyen a los demás; así, algunas teorías indican que los territorios o los bosques, por ejemplo, no son de nadie, es decir, hay ausencia de propiedad sobre estos elementos del ambiente. Por su parte, las teorías liberales (incluyendo las de los conquistadores europeos desde el siglo XVI) indicaban que, al no haber sociedades sedentarias en los territorios conquistados, el derecho de propiedad sobre esos territorios establecía que primero en el tiempo, primero en el derecho, y, por ello, las metrópolis coloniales eran las dueñas o propietarias.

Desde finales del siglo XIX y durante todo el siglo XX se desarrolla de manera amplia la figura del patrimonio común de la humanidad, agenciada especialmente por estados industrializados y empresas multinacionales y transnacionales junto con movimientos ecologistas del Norte industrial, que no fue más que la coartada para que tales estados y empresas se apropiaran indebidamente de los recursos y la diversidad biológica y cultural de otros Estados y sociedades ${ }^{12}$. Por otro lado, el fideicomiso ambiental sobre territorios, suelos y bosques establece que ellos no son patrimonio o propiedad de la generación actual, sino que esta es solo poseedora o buena administradora de los bosques, que son propiedad de las generaciones futuras.

La mayoría de los estados en los tiempos actuales tienen establecida en sus constituciones o sus leyes la propiedad estatal sobre los bosques, las tierras o los suelos, figura reforzada por el Convenio sobre la Diversidad Biológica de 1992, en el cual se

ser humano, en concreto a las culturas que habitan tales ecosistemas (en efecto, un grupo significativo de ellos, considera que los humanos).

${ }^{11}$ La teoría jurídica distingue entre propiedad y soberanía sobre los elementos de la naturaleza; por la visión que estamos defendiendo, tal distinción no es muy relevante en la medida que en las afectaciones a sociedades tradicionales el Estado (propietario o no, o solo con poder soberano sobre el ambiente en su jurisdicción) es responsable por acción o por omisión del cumplimiento de sus deberes y obligaciones ambientales.

${ }^{12}$ Tal es el caso del Tratado de la Antártida, el Tratado de Fondos Oceánicos, el Tratado sobre la luna y demás cuerpos celestes y los intentos en la Cumbre de Río 92 por hacer que Amazonia se consagrara como patrimonio mundial. 
expresa que los recursos genéticos (que están contenidos en los recursos biológicos) son de los Estados donde se encuentran.

Para los efectos de este escrito, destacamos la forma de propiedad colectiva sobre los bosques y otros elementos del ambiente, incluyendo la territorialidad colectiva y la diversidad biológica y cultural que esgrime la idea de propiedad común, comunitaria o social, en el sentido de que el ambiente (incluyendo los territorios, los bosques, las semillas, las aguas, los animales y demás elementos que lo constituyen) es patrimonio o propiedad de los pueblos y sociedades que lo han usado y cuidado ancestral, histórica y tradicionalmente de manera sostenible y que, como pasa con las semillas, puede además estar disponible al servicio de la humanidad, figura jurídica que rompe con el esquema general de uso y apropiación privatística individual de la naturaleza o la generalizada por ecologistas sobre el patrimonio mundial o común.

Tales formas de propiedad colectiva o comunitaria constituyen el modo de producción étnica y campesina, basado en consumos endosomáticos sostenibles para la satisfacción de sus necesidades básicas y no para la acumulación, la depredación y la contaminación que implican los consumos exosomáticos para satisfacer esencialmente "deseos y preferencias humanos" de una pequeña parte de la población mundial, que es la forma "crematística" de acceder a la naturaleza como mera mercancía.

Las anteriores consideraciones nos llevan a preguntarnos por qué, en los tiempos actuales y sobre la base de las formulaciones jurídico-políticas estatales, internacionales y globales, se pretende que las sociedades tradicionales tienen que "adaptarse" al cambio climático. Una primera indicación sería, a su vez, preguntarnos por qué, en primer lugar, no lo hacen los contaminadores y depredadores ${ }^{13}$.

El cambio climático, sus causas y consecuencias orientan la agenda de la comunidad internacional y de sociedades y organizaciones tradicionales, locales, comunitarias, académicas, ambientalistas y ecologistas, empresas, estados y bloques regionales. Tal debate está incompleto si no incorpora una discusión jurídico-política y ética que precise los responsables del deterioro ambiental que origina conflictos y problemas ambientales, expropia, despoja y desplaza forzadamente a personas, sociedades $\mathrm{y}$

\footnotetext{
${ }^{13}$ Como se indica en GARCÍA VEGA, Miguel Angel, "Quién hace caja con el cambio climático", El País, 24 de febrero de 2014, Madrid, Monsanto compró en 2013 Climate Corporation, empresa que suscribe seguros meteorológicos para granjeros y vende información a los agricultores que emplean sus semillas modificadas genéticamente; el capital siempre está pensando en nuevas oportunidades para sus negocios; el cambio climático y, especialmente, sus consecuencias nocivas forman parte de ello.
} 
culturas a otros territorios, Estados o continentes en busca de mejores condiciones de vida, que casi nunca llegan, y, además, seguramente a las metrópolis que provocaron directa o indirectamente (por empresas y Estados) tales desplazamientos.

Los aspectos ambientales de esta conflictividad pasan necesariamente por precisar cómo la Modernidad en los tiempos actuales pone en riesgo ambiental al conjunto de la humanidad presente y futura por sus particulares y específicas formas de expresión del "maldesarrollo" y de un "progreso" a contravía de las posibilidades materiales de la vida digna (humana y no humana), y por ello debería compensar ${ }^{14}$, mitigar, restaurar y hacerse responsable, ambientalmente hablando, de todos los daños e impactos ambientales negativos causados.

Tales cambios, riesgos e impactos concretos, directos e indirectos, inmediatos y mediatos han generado deudas ambientales (naturales y sociales) de unos países, naciones y sociedades con otros, impactando formas de vida concretas y sus condiciones para seguir perviviendo en territorios concretos, generando injusticia ambiental (climática, energética, hídrica, alimentaria, etc.) por huellas ambientales insostenibles de sociedades y Estados responsables del deterioro y la contaminación sin control y cuyas consecuencias las sufren en mayor medida sociedades tradicionales rurales y agrarias ${ }^{15}$.

\footnotetext{
${ }^{14}$ Es necesario tener cuidado con las ideas asociadas a las compensaciones necesarias por los daños e impactos ambientales negativos causados, pues conceptos como los esquemas de compensación de pérdidas de biodiversidad, siguiendo a NADAL, Alejandro, "El arca de Noé se hunde en el mercado financiero", La Jornada, 12 de marzo de 2014, México, están basados en la idea de que la destrucción de un ecosistema en un determinado territorio puede ser compensada con la conservación y/o preservación de un ecosistema similar o comparable en otro lugar. Esta estrategia se basa en considerar la naturaleza un bien fungible usado de manera equivalente en uno $u$ otro lugar, desconociendo la diversidad natural y cultural y los contextos diversos en que se desenvuelve la vida ecosistémica y cultural; por ello, no es adecuada la idea de que la pérdida de biodiversidad puede repararse conservando ecosistemas equivalentes, pues la evolución es diferenciada y hablar de compensaciones de esta manera supone eludir las normas que prohíben el deterioro ambiental o, cuando lo autorizan, eludir los requisitos y estándares del control ambiental cuando los daños se han causado, y la teoría de la responsabilidad ambiental exigente da buena cuenta de los límites necesarios para evitar el deterioro y daño ambiental, como lo indicamos en MESA CUADROS, Gregorio, Derechos ambientales en perspectiva de integralidad: concepto y fundamentación de nuevas demandas y resistencias actuales hacia el Estado ambiental de derecho, Universidad Nacional de Colombia, Bogotá, 2013.

${ }^{15}$ Tales prácticas de sobreexplotación y sobreconsumo consolidan una huella ambiental inadecuada que se traduce, además, en unas deudas ambientales no pagadas y en formas precisas de injusticia ambiental que tienen que ver con extracción y sobreexplotación de recursos naturales de manera exagerada y generalizada, incorporación de sustancias contaminantes más allá de los límites permisibles, exportación de contaminación, intercambios desiguales, biopiratería y desplazamientos ambientales, sin asumir los costos ambientales que todo ello significa y descargando en las víctimas de la depredación y el sobreconsumo, además, la revictimización como responsables principales de los problemas que otros han generado y que, por los efectos del cambio climático por los exagerados consumos de algunos países, impactan más en países con ecosistemas sensibles como los que encontramos en los trópicos (selvas y
} 
Las políticas energéticas y mineras forman parte de una práctica común en los últimos tiempos alrededor de modelos extractivistas que, pese a ser actuales, no significa que no se hayan realizado históricamente y con énfasis específicos en determinados períodos de la historia ambiental del mundo. Tales políticas tienen como consecuencias inmediatas cambios sustanciales en los usos y la ocupación de los territorios y de los elementos del ambiente (suelos, subsuelo, aguas, bosques, fauna, minerales, recursos genéticos, etc.), hábitat principal de pueblos y sociedades tradicionales y rurales, nuevos cambios que están generando múltiples conflictos y problemas ambientales (desplazamientos ambientales, violencias de diverso tipo, persecución y victimización de liderazgos comunitarios o pérdida de autonomía alimentaria, entre otros aspectos) que amenazan seriamente el equilibrio ecosistémico y cultural.

Como indicábamos más arriba, sobre la propiedad y/o posesión de territorios, bosques, aguas y suelos existen múltiples debates alrededor de quién es su propietario y jurídicamente hablando son diversas las teorías al respecto. Desde hace tiempo, grandes cantidades de territorios antes ocupados, poseídos o de propiedad de sociedades tradicionales (recolectoras, agricultoras, pescadoras, pastoras o mineras artesanales) han venido siendo expropiados o comprados mediante engaños de diverso tipo, rompiendo prácticas culturales ancestrales - la mayoría de ellas sostenibles-, reduciendo las posibilidades materiales de seguridad, soberanía y autonomía alimentarias tanto de esas sociedades tradicionales como de los Estados tropicales, y disminuyendo masivamente la cantidad de tierras dispuestas para bosques o para cultivos y pastoreo y reemplazándolos por monocultivos para la exportación o para la extracción mineroenergética.

Es el manejo comunitario ${ }^{16} \mathrm{y}$ colectivo ${ }^{17}$ de territorios, bosques, aguas y otros elementos del ambiente lo que ha permitido su uso y conservación sostenible, aspecto

sabanas ecuatoriales, páramos y subpáramos andinos, humedales y demás zonas de recarga de acuíferos, zonas coralinas y de manglares, entre otros).

${ }^{16}$ Siguiendo a MOLNAR, Augusta. 2013. ¿Propietarios o trabajadores sin tierras? El mundo en transición, un porcentaje superior al $40 \%$ de los bosques del mundo se encuentran en países tropicales y un porcentaje significativo de esos bosques son propiedad de pueblos y sociedades tradicionales (en el caso latinoamericano, más del 18\%); a la mayoría de tales territorios se les han superpuesto o traslapado desde áreas de los sistemas nacionales de áreas protegidas hasta concesiones de hidrocarburos, mineras y de diversos proyectos, obras o actividades extractivas, energéticas o de infraestructura, lo que pone en serio peligro la integridad física y cultural de tales pueblos.

${ }^{17}$ Las sociedades tradicionales, mediante sus prácticas de uso, acceso y conservación de los elementos de la naturaleza, controlan territorios, bienes, espacios y medios de vida, lo que permite su sostenibilidad para las presentes y futuras generaciones no solo de sí mismos, sino también de los demás integrantes de 
de especial importancia para los debates actuales sobre causas y consecuencias de los problemas y conflictos ambientales, incluido el cambio climático, pues son estas sociedades las que han garantizado la persistencia de territorios colectivos con bosques naturales $^{18}$, aguas y suelos como algunos de los principales sumideros de la contaminación atmosférica antropogénica de los países más industrializados, que son los principales responsables de la depredación y contaminación en el mundo durante los últimos dos siglos y que, desde sus particulares visiones, consideran los bosques, pantanos, charcos y humedales, manglares, páramos y selvas como territorios "salvajes" y obstáculos al desarrollo que, por lo tanto, deben ser "civilizados", "domesticados" y "modernizados" bajo la idea de "progreso" y "desarrollo", olvidando que buena parte de las sociedades precolombinas y tradicionales hasta hoy usan de manera sostenible su ambiente, lo que les permite sobrevivir al reconocer las potencialidades y limitaciones de sus ecosistemas, reconociéndose en particular en Colombia la capacidad de sociedades hidráulicas (sinuana) y de montaña (tayronas, u'was, nasas, etc.) para usar adecuadamente la naturaleza.

Pero estas formas de "maldesarrollo" promovidas por estudios contratados con estados, universidades y "expertos" del Norte industrializado solo han mostrado el desconocimiento de los contextos ecosistémicos del trópico, los Andes y las cordilleras americanas y de otros continentes. En los últimos tiempos, los efectos catastróficos de las consecuencias del cambio climático nos muestran las visiones propias de sociedades tradicionales que por centurias han habitado estos territorios y han construido sus estrategias adaptativas al ambiente sobre la base del reconocimiento de sus condiciones ecosistémicas, donde el agua, los bosques, la fauna y la cultura juegan un papel articular y necesario para que la vida siga su curso desde relaciones e intercambios energéticos adecuados, convirtiéndose en ejemplo para el mundo y en un compromiso de los Estados y la sociedad para reconocer política y jurídicamente a estas sociedades y a estos ecosistemas como esenciales para la vida y la supervivencia física, cultural y ambiental de los Estados y la sociedad global, eliminando o disminuyendo los riesgos asociados a los efectos del cambio climático como actual expresión de la crisis

la humanidad. No son prácticas pasadas y olvidadas, sino actuales y persistentes a partir de estrategias de resistencia ambiental comunitaria que se oponen radicalmente a las formas hegemónicas como el capital que pretenden imponerse sobre todo y todos en el mundo.

${ }^{18}$ Usamos el término natural en el sentido de uso sostenible por comunidades tradicionales para diferenciarlo del uso crematístico asociado a las plantaciones forestales. 
ambiental y civilizatoria ${ }^{19}$, signada por la apropiación privatística de bienes públicos, comunes, comunitarios o colectivos, incluso en momentos actuales donde la moda de "teñirse de verde" es el nuevo discurso desarrollista basado en el neoextractivismo generalizado que pretende que todo el ambiente se convierta en mercancía, incluyendo las formulaciones de la "economía verde" y sus "servicios ambientales".

El incremento de los conflictos ambientales actuales tiene en la reprimarización económica y el neoextractivismo minero-energético a uno de sus primeros factores, tal como lo indica el Atlas de Justicia ambiental de EJOLT ${ }^{20}$. Tales impactos ambientales negativos pasan por pasivos ambientales no compensados, inseguridad alimentaria y desplazamientos ambientales forzados y masivos. Persisten paradojas en el discurso actual de la manera como el modelo de desarrollo orientado por el neoextractivismo se enfrenta a la idea de conservación; la moda es teñirse de verde y "regalar" o, peor aún, vender lo que no es de uno, sino de otros, de muchos y de todos, a partir de una estrategia de generalización de la apropiación de la naturaleza, desde las nuevas formas de privatización que, incluso en Río+20, con el discurso de la "economía verde", formulan la apropiación de la naturaleza tanto física como no física, como la venta de servicios ambientales, e incluso virtual, como los mercados de derechos de contaminación $^{21}$.

Pero, en cualquier caso, el quehacer indica que se requiere la construcción de teorías distintas que recuperen la vigencia de lo público, lo común, lo colectivo, lo comunitario,

\footnotetext{
${ }^{19}$ La crisis civilizatoria de la modernidad y su estado actual de cosas es una crisis ambiental resultado de la apropiación y la privatización ilimitada de la naturaleza y la cultura que trae como consecuencias inmediatas crisis alimentarias, energéticas, climáticas, financieras, políticas, sociales y culturales, orientadas por un sistema económico (crematístico, realmente) basado en la apropiación y el despojo sistemáticos del ambiente (ecosistemas y culturas) para favorecer a unos cuantos dueños de los mercados y el capital, resultando banal proponer salidas desde las ideas de progreso y desarrollo, que son, a su vez, la causa central de los conflictos y problemas actuales. No reconocer los límites finitos de la naturaleza y la cultura nos ha llevado al desastre y seguramente nos encamina por la vía del crecimiento ilimitado, con consecuencias catastróficas para los más desfavorecidos de la sociedad del consumo, el deterioro y el desecho.

${ }^{20}$ EJOLT - ENVIRONMENTAL JUSTICE ORGANIZATIONS, LIABILITIES AND TRADE, Atlas global de justicia ambiental, Instituto de Ciencias y Tecnología Ambientales - UAB, Barcelona, 2014 (http://ejatlas.org/).

${ }^{21}$ El pensamiento y la acción ambiental son diversos como diversa es la tonalidad de verdes de ese pensamiento y acción respecto de concebir la naturaleza o el ambiente asociado a la conservación y el cuidado o a la depredación y la contaminación; por ello, los diversos tonos de verde ambiental van desde el más oscuro de los ecologistas radicales hasta el más claro y grisáceo de los ecocapitalistas. Uno de los debates centrales en las dos últimas décadas de vigencia de las propuestas neoliberales es si el capitalismo puede ser verde. Desde nuestra perspectiva indicamos que es una contradicción en los términos: no se puede ser capitalista o neoliberal y ser verde al mismo tiempo, a pesar de que se afirme que sí.
} 
lo que es de todos más allá de las formas actuales; en últimas, una forma de Estado distinto, que, desde nuestra perspectiva, sería el Estado ambiental de derecho, donde la justicia ambiental y la vigencia de los derechos ambientales que desarrollaremos en el siguiente apartado sea el eje de resolución de la indignidad humana y ambiental persistente en el desplazamiento ambiental, reparando y compensando a sus víctimas.

\section{JUSTICIA AMBIENTAL: ELEMENTOS JURÍDICO-POLÍTICOS PARA REPARACIÓN INTEGRAL DE SOCIEDADES TRADICIONALES DESPLAZADAS Y VÍCTIMAS DE CONFLICTOS AMBIENTALES}

Resolver las injusticias ambientales por el uso inadecuado, desproporcionado e ilegal de la naturaleza requiere formulaciones jurídico-políticas y éticas que atiendan el problema de raíz y propongan su resolución desde una perspectiva integral y sistémica, en particular, para evitar que el deterioro y la contaminación persistan y, aun cuando estos se generen, que los delincuentes ambientales (empresas nacionales y transnacionales con la complicidad de Estados depredadores y contaminadores) se perpetúen y persista la impunidad ambiental.

Si estados, empresas y particulares en contextos específicos vistos desde la historia ambiental de la ecosfera han usado abusivamente la naturaleza, las huellas ambientales insostenibles generadoras de deudas ambientales (naturales y sociales) concretas contra pueblos, sociedades y comunidades revictimizadas reclaman ser pagadas, compensadas, mitigadas o restauradas, bajo la idea jurídica de verdad ambiental, justicia ambiental, reparación ambiental y garantía de no repetición ambiental.

A pesar de los avances en los desarrollos jurisprudenciales tanto de la Corte Interamericana de Derechos Humanos como de la Corte Constitucional colombiana, la jurisprudencia de estos dos tribunales todavía carece de visiones integrales porque sigue viendo lo ambiental y la territorialidad étnica y campesina desde una perspectiva sectorial independiente de las visiones sistémicas étnicas, justamente porque parte de fórmulas teóricas basadas en el derecho del Estado-nación como si fuera la única forma de Estado de la modernidad.

En cualquier caso, pueblos y sociedades tradicionales colombianos y latinoamericanos, desde tiempos inmemoriales (como otros pueblos de otros continentes, con más semejanzas que diferencias en sus formas organizativas, políticas, sociales y culturales), 
han configurado sus formas estatales más allá y más acá del Estado-nación. Por otro lado, cualquier diferencia parte necesariamente de la visión ambiental que se tenga, destacándose las visiones integrales de tales pueblos y las visiones sectoriales en el mundo moderno y contemporáneo.

Uno de los elementos clave para la reparación integral de las víctimas del desplazamiento ambiental tiene que ver con la justicia distributiva (es decir, justicia ambiental en estricto sentido), para que los desplazados ambientales no vuelvan a sus situaciones previas o anteriores de indignidad, que se incrementaron con el desplazamiento, sino que, para que realmente pueda ser reparación integral, no se vuelva al estado anterior, sino que se supere, especialmente desde enfoques diferenciales de derechos que tengan en cuenta otros criterios más allá de enfoques basados en teorías liberales de la "igualdad formal" y se transformen en fórmulas prácticas y concretas de "equidad y justicia social", incluyendo la étnica o, mejor aún, empezando por la étnica y campesina, en la medida en que pueblos y sociedades tradicionales usualmente son las poblaciones más vulnerables y, por lo tanto, más afectadas por el desplazamiento ambiental.

La reparación colectiva no debe dejar de lado la distinción entre afectaciones a individuos y afectaciones a colectivos, pueblos o comunidades, ya sea étnicas o campesinas, o sobre la base de otros criterios de diferenciación que permitan concretar especificidades clave para la equidad y la inclusión social — para evitar una doble discriminación o revictimización que usualmente termina favoreciendo a los responsables del desplazamiento ambiental - tales como las formas propias (esencialmente colectivas y comunitarias o comunales) de uso y acceso (prácticas tradicionales) y propiedad sobre territorios, bosques, suelos y demás elementos del ambiente, que deberían formar parte no solo de la necesaria redistribución de bienes para avanzar en equidad, sino también del reconocimiento material de las identidades y diferencias culturales (reconocidas por la Constitución Política o leyes que las desarrollan), rotas por procesos de colonización histórica desde el siglo XVI hasta la fecha que han conllevado desde el desplazamiento ambiental hasta los genocidios étnicos (de indígenas, afros, raizales y palenqueros en Colombia, por ejemplo), cuando no el mero asistencialismo estatal que contribuye a la pervivencia de desigualdades y discriminaciones históricas y actuales. 
Dentro de tales criterios pueden encontrarse, desde el Estado, acciones, omisiones y permisiones, queridas o no queridas o, incluso, no previstas desde el enfoque de las teorías liberales occidentales hegemónicas. Desde los desplazados ambientales (los sujetos a reparar), deberá contarse con su propia y particular mirada, las tipologías y las afectaciones específicas sobre determinados sujetos (la comunidad, los chamanes, los líderes espirituales o cualquier otro tipo de autoridad tradicional, por ejemplo).

Por lo anterior, conceptualmente hablando, el enfoque diferencial es otra mirada de la realidad mucho más amplia y comprensiva de las diferencias, condiciones, prácticas y posiciones específicas (inequidades, exclusiones, desigualdades, discriminaciones, marginaciones, segregaciones) de seres humanos considerados como individuos o como colectivos o grupos poblacionales, las cuales orientan la incorporación de criterios o variables que históricamente han sido desconocidas (pues contribuyen a suspender, negar o violar los derechos ambientales) y cuya puesta en práctica, como línea de acción para el quehacer de la protección efectiva de los derechos, implica reconocimiento tanto de las diversidades culturales y sus necesidades como redistribución material de bienes, servicios y capacidades propias de tales sujetos individuales y principalmente colectivos para la materialización de sus derechos. Por lo anterior, el enfoque diferencial puede implicar diversos criterios a tener en cuenta, entre ellos, el de género y femenino, el étnico y el territorial, la identidad cultural, la diversidad cultural, los usos y las costumbres propios, los sujetos colectivos, el etario, la orientación sexual, las limitaciones o discapacidades ${ }^{22}$, la tipología de la violencia sistemática estatal o no estatal, el rol o papel del afectado...

En cualquier caso, el acervo probatorio que habrá de construirse y presentarse en su momento ante los estados (ya sea la Administración, los jueces o los mecanismos de control del poder público), la comunidad internacional y los organismos de Naciones Unidas, así como ante tribunales internacionales de justicia (Corte Interamericana de Derechos Humanos, Corte Africana de Derechos Humanos, Tribunal Europeo de Derechos Humanos, Corte Internacional de Justicia, Corte Penal Internacional, entre otros), deberá incorporar visiones integrales y sistémicas y no solo datos generales;

\footnotetext{
${ }^{22}$ La afirmación "tenemos el derecho a ser iguales cuando la diferencia nos inferioriza, [y] tenemos el derecho a ser diferentes cuando la igualdad nos descaracteriza" enunciada por SANTOS, Boaventura de Souza, Refundación del Estado en América Latina. Perspectivas desde una epistemología del Sur, Siglo del Hombre, Universidad de los Andes, Siglo XXI, Bogotá, 2010, pág. 76 y 77, es un buen ejemplo de ello.
} 
habida cuenta de que unos pueden ser causa y consecuencia de otros muchos, sus impactos no siempre serán en el corto plazo y, en ocasiones, la capacidad de ser asumidos por las víctimas escapa de las posibilidades materiales de identificarlos y controlarlos .

Desde el punto de vista jurídico-político, consideramos que resolver la indignidad humana y ambiental a la que están sometidos pueblos y sociedades tradicionales que malviven como "desplazados ambientales" pasa necesariamente por dos niveles, la fundamentación material, asociada a la negación de la posibilidad de vivir dignamente por insatisfacción de sus necesidades básicas y permanecer en sus territorios y que las sociedades tradicionales colombianas y latinoamericanas vienen defendiendo desde hace siglos y que desarrollamos en el anterior apartado, y la fundamentación formal o jurídica, basada en derechos y principios ambientales ${ }^{23}$ que desarrollaremos a continuación.

Sobre cómo resolver la indignidad humana y ambiental asociada a pueblos y sociedades tradicionales, queremos destacar la orientación que presentan las normas del Derecho ambiental internacional, así como los principios ambientales.

Una instancia que produce doctrina internacional a tener en cuenta en nuestro debate es el Comité de Derechos Económicos, Sociales y Culturales de la Organización de Naciones Unidas, que adoptó la Observación General núm. 7, acerca de la aplicación del Pacto Internacional de Derechos Económicos, Sociales y Culturales (PIDESC), interpretando el alcance del parágrafo 1 del artículo 11, en mayo de 1997, precisó el concepto de "desalojo forzoso" de esta forma:

Hay otros casos de desalojos forzosos que tienen lugar en nombre del desarrollo ${ }^{24}$.

Pueden efectuarse en relación con conflictos sobre derechos de tierras, proyectos

\footnotetext{
${ }^{23}$ Los principios ambientales como criterios jurídicos y políticos de fines mayores de conservación y cuidado orientan la conducta humana estableciendo una serie de límites o restricciones a ciertas prácticas productivas que generan las erosiones, el deterioro y las contaminaciones del ambiente. La paradoja de tales principios pasa por privilegiar o destacar una práctica no sostenible asociada a la idea de "el que contamina paga" (es decir, consiste en aceptar como idea de principio que la contaminación es imposible de evitar), y, por lo tanto, habrá que pagar por ello. Tal propuesta da como resultado unas autorizaciones usualmente generalizadas para explotar, consumir y contaminar, eludiendo aquellos principios basados en la prevención (no hacer, no explotar, cuidar, conservar, usar con cuidado, consumir solo lo necesario) o en la precaución, en la responsabilidad y en el respeto por la vida.

${ }^{24}$ Según cifras de la Universidad de Naciones Unidas y el Centro Noruego para los Refugiados (2013), por hechos relacionados con el calentamiento global, son más de 144 millones de personas las que se han visto obligadas a dejar sus casas por los efectos del cambio climático entre 2008 y 2012, los cuales, por el incremento significativo de los efectos meteorológicos adversos asociados a inundaciones, tormentas, incendios o sequías, generan, como una de sus consecuencias, los desplazamientos poblacionales
} 
de desarrollo e infraestructura como, por ejemplo, la construcción de presas u otros proyectos energéticos en gran escala, la adquisición de tierras para programas de renovación urbana, rehabilitación de viviendas o embellecimiento de ciudades, el desbroce de tierras para fines agrícolas, la especulación desenfrenada de terrenos o la celebración de grandes acontecimientos deportivos tales como los Juegos Olímpicos.

Igualmente, se indica que los Estados parte deben velar por que se consulte con los interesados todas las posibilidades que permitan evitar o minimizar las afectaciones, así como preservar el derecho a la debida indemnización por los bienes afectados y la garantía a "un recurso efectivo" a aquellos cuyos derechos hayan sido violados.

Además de las anteriores normas que consagran derechos ambientales y doctrina del Comité del PIDESC, consideramos que los principios ambientales pueden orientar en buena medida el quehacer para la reparación integral de los desplazados ambientales. Entre ellos están los principios de responsabilidad, solidaridad, sostenibilidad y globalidad, en la medida en que sirven de criterios para una nueva interpretación de los problemas y conflictos ambientales y su resolución a favor de los afectados por los proyectos, las obras y las actividades que provocan el desplazamiento ambiental de pueblos y sociedades tradicionales en Colombia y Latinoamérica. Algunos de estos principios ambientales ${ }^{25}$ no han sido abordados de manera amplia por las normas nacionales e internacionales ni por la Corte Constitucional colombiana o por la Corte Interamericana de Derechos Humanos - CIDH, pero pueden reorientar enfoques, prácticas y decisiones normativos y judiciales pertinentes al tema en discusión.

El principio de globalidad -que incorpora los principios de integralidad, interdependencia, complejidad y sistematicidad ambientales - precisa que, en los últimos tiempos, los más grandes y graves problemas ambientales tienen un carácter

forzados, ya sea al interior de los Estados o fuera de ellos, y, en este último caso, al no ser considerados refugiados políticos, sus posibilidades de atención son mínimas.

${ }^{25}$ Para un debate en profundidad sobre principios ambientales, véanse MESA CUADROS, Gregorio, Derechos ambientales en perspectiva de integralidad: concepto y fundamentación de nuevas demandas y resistencias actuales hacia el Estado ambiental de derecho, Universidad Nacional de Colombia, Bogotá, 2013, pp. 129 a 141. Igualmente, MESA CUADROS, Gregorio. "Principios ambientales como reglas de organización para el cuidado, la vida, la conservación y el futuro". En: Debates ambientales contemporáneos. (Editor) Bogotá: Editorial Unijus Facultad de Derecho, Ciencias Políticas y Sociales de la Universidad Nacional de Colombia, 2010, pp. 17 a 74 y; JAQUENOD DE ZSÖGÖN, Silvia, El Derecho ambiental y sus principios rectores, Dykinson, Madrid, 1991. De la misma manera, las Declaraciones Universales sobre Ambiente y Desarrollo de Estocolmo 1972, Río de Janeiro 1992 y Johanesburgo 2002 precisan algunos de estos principios y los tratados internacionales en materia ambiental contienen referencias concretas a estos principios. 
global y muchas de las acciones humanas (así como las relaciones entre los ecosistemas y sus diversos componentes) están interconectadas y dependen unas de otras; por ello, una cabal comprensión de estos debe incorporarlos para constatar que los límites naturales (y, por supuesto, menos los artificiales) hoy ya no son una real y efectiva limitación para que los conflictos ambientales se muevan alrededor del globo ${ }^{26}$.

El principio de solidaridad ambiental indica la necesidad de tener en cuenta otros sujetos más allá de los cercanos, ya sea en el tiempo, en el espacio o en la especie; por lo tanto, este principio desarrolla derechos y principios de información, vecindad, cooperación internacional, igualdad y patrimonio universal, $\mathrm{y}$, a su vez, se conoce como principio de solidaridad entre los pueblos, superando visiones reduccionistas $\mathrm{y}$ sectoriales donde la solidaridad como fundamento de los derechos esté más allá de la solidaridad entendida con relación al grupo o solo a unos humanos. Por ello, nuestra perspectiva indicará una triple condición que permita hacer contribuciones sustanciales para resolver conflictos ambientales: solidaridad subjetiva con nuevos sujetos o ampliación del ámbito de moralidad a no humanos, como postulan las sociedades tradicionales en Colombia; solidaridad en el tiempo o solidaridad sincrónica y diacrónica, pues los derechos deben predicarse materialmente tanto para las generaciones actuales como para las futuras; y solidaridad en el espacio, donde el límite estrecho de vigencia espacial o territorial de los derechos debe ser ampliado en el sentido de globalidad a todos los habitantes de la tierra independientemente de su nacionalidad.

Por ello, el principio de solidaridad y equidad intrageneracional, intergeneracional y transgeneracional reclama una nueva visión sobre la responsabilidad y solidaridad, junto con obligaciones con el presente y el futuro, con quienes todavía no existen y con los que hoy no tienen ni pueden; por lo tanto, consiste en el derecho que tienen tanto las generaciones actuales como las futuras para satisfacer sus propias necesidades.

Por otro lado, el principio de responsabilidad ambiental precisa que la protección del ambiente y sus elementos compete no solo al Estado y a sus distintas autoridades, sino también a los particulares, incluyendo las empresas y todos aquellos que tienen la

\footnotetext{
${ }^{26}$ Asimismo, los conflictos ambientales se caracterizan por sus altos niveles de complejidad (a partir de la multiplicidad de conexiones, interrelaciones e interdependencias entre sus diversos elementos o componentes) y son, además, causa o consecuencia de otros problemas ambientales, están relacionados y presentan interconexiones entre sí, y adquieren un carácter generalizado o grave por los efectos acumulativos de estos.
} 
capacidad de afectar al ambiente. De ahí la doble expresión de este principio, el de responsabilidades compartidas pero diferenciadas de acuerdo con la conducta o actuación específica de cada actor, y el principio de la responsabilidad ambiental "de la cuna a la tumba" o responsabilidad pensada en un enfoque temporal que asume el "ciclo de vida del producto", entendiendo que quien incorpora algo en el ambiente se hace responsable desde el momento en que ingresa ese producto en el ambiente hasta el momento en que este deja de producir efectos ambientales negativos y que se traduce en derechos de generaciones actuales y futuras tanto en el medio como en el largo plazo según la intensidad y permanencia del impacto ambiental.

Desde lo interestatal, el principio de responsabilidad y reparación del daño ambiental indica que los Estados son responsables por la comisión de actos ilícitos o la omisión de los deberes estatales que violan normas ambientales internacionales, por lo que deberán reparar, indemnizar, compensar y mitigar los daños o la contaminación producidos, y, específicamente, el principio de responsabilidades compartidas pero diferenciadas, ya que la responsabilidad ambiental es común a todos los Estados, pero se diferencia de acuerdo con sus prácticas e intervenciones en su ambiente, en el de los demás Estados o en el ambiente global, por lo que deberán responder de manera distinta en la prevención, reducción, mitigación o compensación de los daños ambientales.

El principio de prevención ambiental se define como aquel aspecto jurídico que busca evitar el daño o el deterioro antes que controlar o reparar lo realizado, que puede ser irreparable. Este principio se encuentra formulado en el artículo 80 de la Constitución colombiana de 1991, junto con el principio de precaución ambiental, que al año siguiente el numeral 15 de la Declaración de Río formuló con el fin de proteger el ambiente y que establece que los Estados deberán aplicar ampliamente el criterio de precaución conforme a sus capacidades y que, cuando haya peligro de daño grave o irreversible, la falta de certeza científica absoluta no deberá utilizarse como razón para postergar la adopción de medidas eficaces en función de los costos para impedir la degradación del ambiente.

En el ámbito interestatal, el principio de prevención está basado en las indicaciones de la buena fe, la buena vecindad, la diligencia debida y el uso sostenible y equitativo de los recursos naturales; este principio se precisa desde dos vertientes, la prevención del daño ambiental in genere y la prevención del daño ambiental transfronterizo. Este principio es diferente de la precaución, que implica tomar medidas sobre la base de la 
información científica acumulada y adoptar medidas ambientales preventivas; por ello, el principio de precaución precisa que, cuando exista peligro de daño grave, inminente o irreversible, la falta de certeza científica absoluta no deberá invocarse como excusa para que los Estados no tomen las medidas correspondientes de protección ambiental.

Existiendo otros múltiples principios ambientales, destacamos el principio de sostenibilidad ambiental, respecto al cual la Declaración de Río, en su numeral 3, afirma que el derecho al desarrollo debe ejercerse de forma tal que responda equitativamente a las necesidades de desarrollo y ambientales de las generaciones presentes y futuras; aun así, sigue sin resolverse del todo la primacía del "desarrollo sostenible", que entiende el desarrollo como crecimiento económico que siempre se impone sobre la conservación (sostenibilidad). Por lo tanto, consideramos, siguiendo a Daly $^{27}$, la sostenibilidad no solo como "desarrollo sostenible", sino también como el conjunto de límites al proceso productivo, en particular, la irreversibilidad cero, la extracción y vaciado o emisión sostenibles, así como la selección sostenible de tecnologías.

Sobre este principio, los Estados deberán avanzar en el proceso de transferir recursos suficientes a las generaciones venideras de manera que sus integrantes sean tan prósperos como la generación actual, y, para que ello sea posible, se requiere limitar el proceso productivo y las formulaciones sobre el desarrollo, contando con instituciones intergubernamentales que protejan los bienes comunes y no solo la apropiación privada.

En el ámbito internacional, algunos de los anteriores principios ambientales han tenido un desarrollo más amplio ${ }^{28}$; en efecto, ya desde la Declaración de Estocolmo de 1972, pero especialmente con la Declaración de Río sobre Ambiente y Desarrollo (1992), Johannesburgo (2002), Río (2012) y otros tratados y acuerdos internacionales de diverso tipo en temáticas ambientales generales y específicas, se vienen consolidando una serie de directrices y parámetros que configuran lo que podría denominarse un “estándar ambiental global”, basado en criterios o valores ambientales de especial relevancia que todavía no logran concretarse.

\footnotetext{
${ }^{27}$ Tal como lo precisa en DALY, Herman E., "Criterios operativos para el desarrollo sostenible", Debats, 35-36, 1991, pp. 39-41.

${ }^{28}$ Para un debate en profundidad sobre este tema, véase MESA CUADROS, Derechos ambientales en perspectiva de integralidad: concepto y fundamentación de nuevas demandas y resistencias actuales hacia el Estado ambiental de derecho, p.129.
} 
De los principios ambientales internacionales destacamos, además, el principio del patrimonio común de la humanidad, según el cual el ambiente en general o elementos o componentes del ambiente (Antártida, fondos oceánicos) pertenecen a toda la humanidad, sea presente o futura; el principio de soberanía estatal o patrimonio estatal ambiental, o principio de soberanía estatal sobre los recursos naturales; el principio de cooperación, o de deberes de los Estados para asistencia mutua; y el principio de justicia internacional, como justicia ambiental global que orienta nuestro debate en este escrito.

Por otro lado, encontramos el principio de resolución pacífica de controversias, que establece que los conflictos ambientes interestatales deberán resolverse de manera acordada y no por la fuerza, y el principio de evaluación de impactos ambientales, que precisa que, para la toma de decisiones en materia ambiental, deberá contarse con instrumentos y estudios técnicos que orienten la toma de decisiones. De otra parte, tenemos el principio de subsidiariedad, según el cual las decisiones ambientales provendrán de las comunidades más afectadas o, en su defecto, de las autoridades más cercanas a ellas.

Pero quizás el principio que más se cumple sea un antiprincipio, el principio "quien contamina paga", por el que el Estado causante de la contaminación deberá asumir (por ello, también se conoce como principio de internalización de los costos ambientales o principio contaminador - pagador) los costos ambientales que esa contaminación generó.

Además de los derechos ambientales protegidos en normas nacionales e internacionales que orientarían la reparación de las víctimas del desplazamiento ambiental, se cuenta con la jurisprudencia. Para el caso que nos ocupa, consideramos relevante tanto la defendida por la Corte Interamericana de Derechos Humanos (CIDH) como por la Corte Constitucional colombiana.

Esta última, en la Sentencia T-135 de 2013, precisa que la construcción de grandes obras de infraestructura implica el surgimiento de situaciones extraordinarias para las poblaciones concernidas, especialmente porque las obliga a someterse a modificaciones sustanciales en sus vidas; tales cambios están autorizados por una decisión gubernamental que busca, por ejemplo, resolver necesidades energéticas del país y que "amenaza por sí misma derechos fundamentales de dichas personas y puede ponerlos en situación de violación"; pero las necesidades energéticas del país (que pueden estar bajo 
el ámbito del principio constitucional de prevalencia del interés general — según lo precisa el artículo $1 .^{\circ}$ de la Constitución colombiana-) no pueden servir de excusa para la violación de los derechos de los asociados, estando entre tales derechos el derecho a gozar de un ambiente sano, el derecho a la vida digna, el derecho al mínimo vital, el derecho a la vivienda digna, el derecho al trabajo, el derecho a la seguridad alimentaria y el derecho a la participación.

Para el caso que nos ocupa, es pertinente, además, remitirnos a lo establecido por la Corte Constitucional colombiana en su Sentencia C-715 de 2012 al hablar de derechos de las víctimas del desplazamiento forzado interno y retomar algunas de sus líneas y principios de argumentación a favor de los derechos de los desplazados y despojados ambientales como víctimas de los responsables del deterioro del ambiente, incluido el cambio climático antropogénico pasado, actual y futuro.

En esta sentencia, la Corte Constitucional colombiana ha venido consolidando y precisando los criterios, principios, reglas y subreglas al analizar la constitucionalidad ${ }^{29}$ de ciertas leyes, así como al analizar en sede de tutela los derechos de las víctimas a la verdad, a la justicia y a la reparación integral, que en la sentencia en mención sintetiza y ejerce la labor de unificación jurisprudencial de dichos criterios y reglas.

Por lo anterior, consideramos que la mayoría de criterios sobre reparación integral de las víctimas del conflicto armado interno y las prescripciones normativas de algunos instrumentos jurídicos internacionales relevantes enunciados por la Corte podrían ser tenidos en cuenta por analogía o directamente — sobre todo si partimos de una teoría de la integralidad de los derechos como la defendida por nosotros ${ }^{30}$ - para traducir la justicia ambiental que defendemos, al reconocer los derechos de las víctimas a la justicia, la verdad, la reparación y la garantía de no repetición de las conductas generadoras de daños e impactos ambientales negativos sobre pueblos, comunidades y sociedades vulnerables en mayor medida a la conflictividad ambiental.

\footnotetext{
${ }^{29}$ Para ello, contrasta los derechos incorporados en las normas de los artículos 1, 2, 15, 21, 93, 229 y 250 de la Constitución de 1991, los criterios del derecho internacional humanitario y los estándares del derecho internacional de los derechos humanos respecto de los derechos de las víctimas y previos pronunciamientos jurisprudenciales como los establecidos en la Sentencia C-578 de 2002, en revisión de la Ley 742, de 2002, que aprobó el Estatuto de Roma de la Corte Penal Internacional; en la Sentencia C580 de 2002, que revisó la constitucionalidad de la Ley 707, de 2001, aprobatoria de la Convención Interamericana sobre Desaparición Forzada de Personas; en la Sentencia C-370 de 2006 y la Sentencia C1199 de 2008, sobre demanda de inconstitucionalidad de partes de la Ley 975, de 2005, sobre "reincorporación de miembros de grupos armados organizados al margen de la ley", entre otras.
}

${ }^{30}$ Ibid., pp.141 y ss. 
Dentro de tales instrumentos jurídicos internacionales se encuentran la Declaración Universal de Derechos Humanos —art.8-, la Declaración Americana de los Derechos y Deberes del Hombre - art. 23-, la Declaración sobre los principios fundamentales de justicia para las víctimas de delitos y del abuso del poder —arts. 8 y $11-$, el Protocolo II adicional a los Convenios de Ginebra — art. 17-, el Conjunto de principios para la protección y la promoción de los derechos humanos mediante la lucha contra la impunidad o "principios Joinet" —arts. 2, 3, 4 y 37-, la Convención Americana sobre Derechos Humanos, la Declaración de Cartagena sobre Refugiados, la Declaración de San José sobre Refugiados y Personas Desplazadas, y la Convención sobre el Estatuto de los Refugiados de Naciones Unidas y su Protocolo Adicional, así como la Resolución 60/147 de Naciones Unidas, sobre principios y directrices básicos del derecho de las víctimas de violaciones manifiestas de las normas internacionales de derechos humanos y de violaciones graves del Derecho internacional humanitario a interponer recursos y obtener reparación adecuada, efectiva y rápida del daño sufrido, pues son conocidos los daños sufridos por estas, que demandan que la reparación debe ser justa, suficiente, efectiva, rápida y proporcional a la gravedad de las violaciones y a la entidad del daño sufrido.

Asimismo, es de destacar que la Corte Constitucional de Colombia es prolífica en enunciar en la Sentencia C-715 de 2012 los derechos de las víctimas a la verdad, a la justicia y a la reparación integral en el marco del derecho internacional, el derecho internacional humanitario y el derecho internacional de los derechos humanos, de conformidad con el artículo 93 de la Constitución Política, que incorpora el bloque de constitucionalidad $^{31}$ recogiendo especialmente la Resolución 60/147 de Naciones Unidas y sus principios básicos sobre el derecho de las víctimas a interponer recursos y obtener reparaciones, así como el numeral 1. ${ }^{\circ}$ del artículo 63 de la Convención Americana sobre Derechos Humanos y su derecho fundamental a obtener una "reparación adecuada, efectiva y rápida del daño sufrido", el cual puede haberse generado con ocasión de vulneración masiva y sistemática de derechos, generando o

\footnotetext{
${ }^{31}$ Los tratados y convenios internacionales ratificados por el Congreso de Colombia y que reconocen los derechos humanos y prohíben su limitación en los estados de excepción prevalecen en el orden interno. Por otro lado, los derechos constitucionales deben ser interpretados de conformidad con los tratados de derechos humanos ratificados por Colombia. Por ello, la Corte enfatiza que la jurisprudencia de las instancias internacionales de derechos humanos, como la de la Corte Interamericana de Derechos Humanos, tiene una especial relevancia constitucional por cuanto constituye una pauta hermenéutica para interpretar el alcance de tratados como la Convención Americana sobre Derechos Humanos y, por ende, de los propios derechos constitucionales.
} 
continuando situaciones de vulnerabilidad, debilidad, desigualdad y condiciones mínimas de existencia a quienes hay que reparar.

Igualmente, la Corte Constitucional colombiana retoma la jurisprudencia de la Corte Interamericana de Derechos Humanos que reconoce y protege los derechos de las víctimas de graves violaciones de los derechos humanos consagrados en la Convención Americana sobre Derechos Humanos, en particular, los derechos a la justicia, a la verdad, a la reparación y a la garantía de no repetición y sus conexos e interrelacionados.

Sobre el "reconocimiento y reparación de los derechos de las víctimas", la CIDH ${ }^{32}$ ha reiterado que ello implica por parte de los Estados tomar, por lo menos, las siguientes medidas:

(i) Prevenir los atentados y las violaciones de derechos humanos.

(ii) Una vez ocurrida la violación, garantizar el acceso a un recurso judicial sencillo y eficaz por parte de las víctimas.

(iii) Investigar y esclarecer los hechos ocurridos.

(iv) Perseguir y sancionar a los responsables de manera oficiosa, pronta, efectiva, seria, imparcial y responsable.

(v) Adelantar los recursos judiciales, con respeto del debido proceso, dentro de un plazo razonable.

(vi) Establecer la incompatibilidad de figuras jurídicas tales como la prescripción, la exclusión de la pena o amnistías, con graves violaciones de los derechos humanos.

(vii) Prevenir y combatir la impunidad (es decir, la falta de investigación, persecución, captura, enjuiciamiento y condena de los responsables de las violaciones de los derechos protegidos por la Convención Americana).

\footnotetext{
${ }^{32}$ Tales medidas han sido enunciadas y reiteradas por la corte en diversas sentencias, entre otras, véase CORTE INTERAMERICANA DE DERECHOS HUMANOS (CIDH), Caso Pueblo Saramaka vs. Surinam. (Excepciones preliminares, fondo, reparaciones y costas). Sentencia de 28 de noviembre de 2007, Serie C núm. 172. - Caso Comunidad Indígena Sawhoyamaxa vs. Paraguay. (Fondo, reparaciones y costas). Sentencia de 29 de marzo de 2006, Serie C núm. 146. Caso Comunidad Indígena Yakye Axa vs. Paraguay. (Interpretación de la Sentencia de Fondo, reparaciones y costas). Sentencia de 6 de febrero de 2006, Serie C núm. 142. Caso Comunidad Indígena Yakye Axa vs. Paraguay. (Fondo, reparaciones y costas). Sentencia de 17 de junio de 2005, Serie C núm. 125. Caso Comunidad Mayagna (Sumo) Awas Tigni vs. Nicaragua. (Fondo, reparaciones y costas). Sentencia de 31 de agosto de 2001, Serie C núm. 79.
} 
(viii) No aceptar amnistías cuando la gravedad de las consecuencias que conlleva la impunidad, tales como la repetición crónica de las violaciones y la indefensión de las víctimas y sus familiares, promovería nuevas vulneraciones.

Desde nuestra perspectiva, el derecho a la justicia ambiental incorpora el derecho a la verdad, y en este derecho son relevantes la verdad histórica, la verdad política y la verdad judicial tanto para reconocer los daños, las faltas y los delitos e impactos cometidos desde hace décadas y centurias como los que están en curso y el Estado y la comunidad internacional no ayudan a resolver.

Para su concreción, los derechos a la verdad, la justicia, la reparación y la garantía de no repetición, como derechos que configuran en parte la idea de justicia ambiental en sentido estricto, deben contar con la participación activa y decisora de los pueblos, comunidades y sociedades concernidos, incluyendo los derechos de consulta previa con consentimiento previo, libre e informado, las audiencias públicas generales y específicas a que haya lugar, los estudios de impacto ambiental, las evaluaciones de impacto ambiental, los planes de manejo, evaluación, seguimiento y control ambiental, incluyendo los de abandono de obras y, sobre todo, la reparación de pasivos ambientales (tanto ecosistémicos como culturales), bajo el entendido de que, como ha indicado la Corte Constitucional en diversas sentencias y la Corte Interamericana de Derechos Humanos, los derechos de pueblos y sociedades tradicionales puedan ser restaurados y los daños causados, compensados o mitigados, así como prevenidos los eventuales daños futuros.

En el caso del derecho a la verdad, tanto la Corte Interamericana de Derechos Humanos $(\mathrm{CIDH})$ como la Corte Constitucional colombiana ${ }^{33}$ han afirmado que este derecho

\footnotetext{
${ }^{33}$ Sobre el derecho a la verdad, la Corte Constitucional colombiana en su Sentencia C-715 de 2012 mencionada más arriba, ha establecido los siguientes criterios jurisprudenciales:

[...] “(i) El derecho a la verdad, consagrado en los principios 1 a 4 de los Principios para la protección y promoción de los derechos humanos mediante la lucha contra la impunidad, encuentra su fundamento en el principio de dignidad humana, en el deber de memoria histórica y de recordar, y en el derecho al bueno nombre y a la imagen;

(ii) las víctimas y los perjudicados por graves violaciones de derechos humanos tienen el derecho inalienable a saber la verdad de lo ocurrido;

(iii) este derecho se encuentra en cabeza de las víctimas, de sus familiares y de la sociedad en su conjunto, y por tanto apareja una dimensión individual y una colectiva;

(iv) la dimensión individual del derecho a la verdad implica que las víctimas y sus familiares conozcan la verdad sobre los hechos, los responsables y las consecuencias de lo sucedido. Este derecho apareja por
} 
contiene múltiples derechos, entre otros: (i) el derecho de las víctimas y de sus familiares a conocer la verdad real sobre lo sucedido; (ii) a saber quiénes fueron los responsables de los atentados y las violaciones de los derechos humanos; y (iii) a que se investigue y divulgue públicamente la verdad sobre los hechos. Asimismo, el derecho a la verdad se predica tanto de las víctimas y sus familiares como de la sociedad como un todo, y entre el derecho a la verdad, el derecho a la justicia y el derecho a la reparación existe conexidad intrínseca.

Igualmente, sobre el derecho a la justicia es conocida la jurisprudencia de la CIDH, quien ha reiterado que este derecho implica, por una parte, una obligación de prevención de los atentados y las violaciones de los derechos, $\mathrm{y}$, por otra, una vez ocurrida la violación, la garantía de acceso a un recurso judicial sencillo y eficaz por parte de las víctimas, lo cual supone a su vez la obligación de los Estados parte de investigar y esclarecer los hechos ocurridos, así como la de perseguir y sancionar a los

tanto, el derecho a conocer la autoría del crimen, los motivos y las circunstancias de tiempo, modo y lugar en que ocurrieron los hechos delictivos, y finalmente, el patrón criminal que marca la comisión de los hechos criminales. Esto último, implica el derecho a conocer si el delito que se investiga constituye una grave violación a los derechos humanos, un crimen de guerra o un crimen de lesa humanidad;

(v) la dimensión colectiva del derecho a la verdad, por su parte, significa que la sociedad debe conocer la realidad de lo sucedido, su propia historia, la posibilidad de elaborar un relato colectivo a través de la divulgación pública de los resultados de las investigaciones, e implica la obligación de contar con una 'memoria pública' sobre los resultados de estas investigaciones sobre graves violaciones de derechos humanos;

(vi) el derecho a la verdad constituye un derecho imprescriptible que puede y debe ser garantizado en todo tiempo;

(vii) con la garantía del derecho a la verdad se busca la coincidencia entre la verdad procesal y la verdad real;

(viii) este derecho se encuentra intrínsecamente relacionado y conectado con el derecho a la justicia y a la reparación. Así, el derecho a la verdad se encuentra vinculado con el derecho de acceso a la justicia, ya que la verdad sólo es posible si se proscribe la impunidad y se garantiza, a través de investigaciones serias, responsables, imparciales, integrales y sistemáticas por parte del Estado, el consecuente esclarecimiento de los hechos y la correspondiente sanción;

(ix) de otra parte, el derecho a la verdad se encuentra vinculado con el derecho a la reparación, ya que el conocimiento de lo sucedido para las víctimas y sus familiares, constituye un medio de reparación;

(x) los familiares de las personas desaparecidas tienen derecho a conocer el destino de los desaparecidos y el estado y resultado de las investigaciones oficiales. En este sentido, el derecho a conocer el paradero de las personas desaparecidas o secuestradas se encuentra amparado en el derecho del familiar o allegado de la víctima a no ser objeto de tratos crueles, inhumanos o degradantes y debe ser satisfecho, incluso, si no existen procesos penales en contra de los presuntos responsables (por muerte, indeterminación o cualquier otra causa);

(xi) la importancia y la obligación del Estado de adelantar investigaciones criminales con el fin de esclarecer la responsabilidad penal individual y la verdad de los hechos, sino también la importancia de mecanismos alternativos de reconstrucción de la verdad histórica, como comisiones de la verdad de carácter administrativo, que en casos de vulneraciones masivas y sistemáticas de los derechos humanos, deben servir a los fines constitucionales antes mencionados". 
responsables, accionar que debe desarrollarse de manera oficiosa, pronta, efectiva, seria, imparcial y responsable por parte de los Estados, con recursos judiciales adelantados con respeto del debido proceso, dentro de un plazo razonable, y que prescripciones, exclusiones de penas o amnistías pueden ser a su vez violaciones de los derechos de las víctimas.

Sobre el derecho a la reparación ${ }^{34}$, la Corte Constitucional ha fijado criterios, principios, parámetros y estándares constitucionales, en armonía con el derecho y la jurisprudencia internacional, reiterando especialmente lo indicado por la CIDH en la materia; por ello, destacamos especialmente lo dicho por esta última y que puede ser el insumo básico para pensar una reparación integral a pueblos y sociedades tradicionales afectados por la conflictividad ambiental provocada por proyectos, obras o actividades en sus territorios, bosques, aguas y demás elementos ambientales que violan principios y derechos reconocidos constitucional y legalmente y a los que el Estado y la comunidad internacional deberían responder.

La Corte Constitucional colombiana y la CIDH han determinado que el derecho a la reparación contiene, por lo menos, las siguientes consideraciones y principios: (i) reparaciones integrales y plenas para garantizar la restitución de las víctimas al estado anterior al hecho vulneratorio; (ii) indemnizaciones compensatorias de no ser posible la restitución integral y plena; (iii) reparación justa y proporcional al daño sufrido; y (iv) reparación tanto de daños materiales como inmateriales. La reparación del daño material incluye tanto el daño emergente como el lucro cesante, así como medidas de rehabilitación, y la reparación debe tener un carácter tanto individual como colectivo, este último referido a medidas reparatorias de carácter simbólico. Estos elementos son de vital importancia para reparar a las víctimas de los impactos ambientales negativos sobre pueblos, sociedades y comunidades tradicionales ${ }^{35}$.

\footnotetext{
${ }^{34}$ Afirma la Corte Constitucional en su Sentencia C-715 de 2012 que la reparación "tiene como título la comisión de un ilícito, la ocurrencia de un daño antijurídico y la grave vulneración de los derechos humanos, razón por la cual no se puede sustituirlas o asimilarlas, aunque una misma entidad pública sea responsable de cumplir con esas funciones, so pena de vulnerar el derecho a la reparación"; por ello, no puede ser confundida con asistencia y servicios sociales o con la ayuda humanitaria brindada por parte del Estado.

${ }^{35}$ Para que las reparaciones sean integrales y plenas, es decir, se garantice la restitutio in integrum (restitución de las víctimas al estado anterior al hecho vulneratorio), no se debe olvidar que pueblos y sociedades tradicionales han visto vulnerados históricamente sus derechos, por lo que la idea no es volver a estados anteriores de discriminación y desconocimiento, sino que lo integral deberá dar cuenta de superar tales violaciones históricas y avanzar en la equidad desde enfoques diferenciales que promuevan todos sus derechos.
} 
La reparación a estos pueblos y sociedades tradicionales incorpora una serie de "medidas de indemnización", y respecto de estas, la CIDH ha desarrollado en su jurisprudencia el concepto de daño material ${ }^{36} \mathrm{e}_{\text {inmaterial }}^{37}$ y los supuestos en que corresponde indemnizarlos, tanto por negarles los derechos al territorio y a sus propios recursos naturales como por denigrar o desconocer los valores culturales y espirituales asociados al ambiente en el que viven, así como sus especiales formas de territorialidad y usos y acceso diferenciado a los elementos ambientales que lo constituyen. En el Caso del Pueblo Saramaka vs. Surinam (2007), la Corte ordena que el Estado asigne sumas dinerarias para indemnizar tanto por daños materiales como por daños inmateriales y establece la creación de un fondo de desarrollo comunitario Saramaka ${ }^{38}$.

En el párrafo 205 de la Sentencia de 17 de junio de 2005, Caso Comunidad Indígena Yakye Axa vs. Paraguay, la CIDH considera que la posesión de la territorialidad tradicional Yakye Axa “está marcada de forma indeleble en su memoria histórica y la relación que mantienen con la tierra es de una calidad tal que su desvinculación de la misma implica riesgo cierto de una pérdida étnica y cultural irreparable, con la consecuente vacante para la diversidad que tal hecho acarrearía", por lo que, al haberlo perdido, es deber del Estado identificar ese territorio tradicional y entregarlo de manera gratuita a la comunidad Yakye Axa en un plazo máximo de tres años. En caso de estar en manos privadas, el Estado deberá valorar la eventual expropiación de esas tierras (pudiendo crear un fondo para tal fin) y, para ello, deberá tomar en cuenta los usos y las costumbres Yakye Axa. Por último, solo si por motivos objetivos y fundamentados la reivindicación del territorio ancestral no fuera posible, deberá entregarle tierras

\footnotetext{
${ }^{36}$ En el caso en discusión, se probó que, con autorización estatal y sin consulta previa a los Saramaka, algunas empresas extrajeron del bosque del pueblo Saramaka cantidades considerables de madera, lo que afectó a los derechos e intereses Saramaka.

${ }^{37}$ Los daños e impactos a la territorialidad étnica y a los elementos del ambiente que le son comunes (bosques, aguas, fauna, suelos) afectan no solo a los elementos ambientales físicos de los cuales dependen las comunidades para sobrevivir, sino que, por su especial concepción cultural, las conexiones espirituales, religiosas y cosmogónicas con su ambiente (bosques, lagunas, ríos, quebradas, montañas, animales, etc.) afectan en mayor medida a la vulnerabilidad de estos pueblos y sociedades tradicionales, sometidos a graves vejaciones, sufrimientos, violaciones y angustias que se tornan insoportables al desconocer valores no meramente crematísticos, sino esencialmente culturales y, no contar con la protección del Estado o de la sociedad, además de ver que la conflictividad persiste y no se avizoran mecanismos para su resolución y protección efectiva.

${ }^{38}$ El fondo (creado y establecido en beneficio de los Saramaka en su territorio tradicional) estará diseñado y estructurado en consulta con la comunidad, será desarrollado según sus usos y costumbres, y deberá financiar diversos proyectos (educativos, habitacionales, agrícolas, de saneamiento y agua potable y de infraestructuras básicas) orientados por un comité de tres miembros (uno nombrado por los Saramaka, otro por el Estado y el tercero de común acuerdo) que deberá consultar al pueblo Saramaka antes de tomar decisiones.
} 
alternativas suficientes para garantizar el mantenimiento y desarrollo de la propia forma de vida comunitaria, las cuales serán definidas de modo consensuado con la comunidad conforme a sus propias formas de consulta y decisión.

Por otro lado, es pertinente indicar la referencia explícita a las "reparaciones comunitarias" y no solo individuales que la CIDH realiza en el párrafo 80 de la Sentencia de 19 de noviembre de 2004, Caso Masacre Plan de Sánchez vs. Guatemala, ya que las víctimas del caso en mención pertenecen a un pueblo indígena ${ }^{39}$ y por ello se hace necesario reparar e indemnizar por los derechos colectivos ${ }^{40}$, además de por los derechos individuales; por lo tanto, las reparaciones no se agotan con la indemnización de los daños materiales e inmateriales, sino con otras formas de reparación, en particular, aquellas que denomina "medidas de satisfacción", que, por la gravedad y el carácter colectivo de los daños generados, buscan reparar el daño inmaterial y no tienen alcance pecuniario. Algunas de tales medidas son:

a) Investigación: obligación de investigar hechos generadores de las violaciones, identificando, juzgando y sancionando a los responsables, para superar la impunidad que propicia la repetición crónica de las violaciones de los derechos humanos de las víctimas.

b) Memoria y desagravio: realización por parte del Estado y de terceros de actos públicos de reconocimiento de responsabilidad internacional en desagravio de las víctimas y en memoria de las personas ejecutadas en la masacre, traducción de las sentencias de la Corte en el idioma indígena, publicación y difusión en medios de comunicación de las partes pertinentes de las sentencias de la Corte, por ejemplo.

\footnotetext{
${ }^{39}$ Recuerda la Corte que, como culturas diferenciadas, los pueblos y las sociedades tradicionales como el que demanda poseen autoridades tradicionales y formas de organización comunitaria propias, centradas en el acuerdo de voluntades colectivas y el respeto, así como sus propias estructuras sociales, económicas y culturales, en las que la armonía con el ambiente se expresa por la relación espiritual que tienen con la tierra, la forma de manejo de los recursos y el profundo respeto a la naturaleza, y donde las tradiciones, los ritos y las costumbres tienen un lugar esencial en su vida comunitaria, espiritualidad que se refleja en la estrecha relación entre los vivos y los muertos y la práctica de los rituales de entierro como una forma de permanente contacto y solidaridad con sus antepasados y la transmisión de la cultura y del conocimiento como rol esencial asignado a los mayores, hombres y mujeres.

${ }^{40}$ Consideramos que la CIDH, en el caso del Pueblo Saramaka vs. Surinam, párrafo 200 de la Sentencia, al indicar que los impactos y daños ambientales causan graves alteraciones en los vínculos colectivos comunitarios y, por ello, deben ser reparados y compensados, pretende incorporar una visión de derechos colectivos que a su vez deben ser protegidos y reparados.
} 
c) Memoria colectiva: para la garantía de no repetición, el Estado deberá dotar de recursos para la memoria colectiva y el tratamiento médico y psicológico individual y colectivo.

d) Dotación de recursos: para el desarrollo de los propios planes de vida comunitarios, el Estado deberá organizar programas de desarrollo en salud, educación, vivienda, producción e infraestructura de acuerdo con las necesidades comunitarias y de sus integrantes, siguiendo protocolos específicos de acuerdo con los usos y las costumbres comunitarios.

Una síntesis amplia de los diversos deberes estatales para reparar a las víctimas individuales y colectivas de graves violaciones a sus derechos fue precisada por la CIDH en el párrafo 209 de la Sentencia de 15 de junio de 2005, Caso de la Comunidad Moiwana vs. Surinam. Así, algunas de las medidas son las siguientes:

a) Título colectivo a las tierras tradicionales: deber de otorgar títulos colectivos sobre las tierras tradicionales de pueblos y comunidades étnicos, respondiendo al mandato del artículo 21 de la Convención Americana de adoptar "todas las medidas legislativas, administrativas y de cualquier otra índole necesarias para asegurar a los miembros [de pueblos y comunidades étnicas] su derecho de propiedad sobre los territorios tradicionales de los que fueron expulsados y asegurar, por lo tanto, el uso y goce de estos territorios", medidas que deberán incluir "la creación de un mecanismo efectivo para delimitar, demarcar y titular dichos territorios tradicionales" y con "la participación y el consentimiento informado de las víctimas, expresado a través de sus representantes", así como "abstenerse de realizar acciones — ya sea por parte de agentes estatales o de terceros que actúen con la aquiescencia o tolerancia del Estado- que afecten la existencia, valor, uso o goce de la propiedad ubicada en el área geográfica donde vivieron tradicionalmente los miembros de la comunidad".

b) Garantías estatales de seguridad para los miembros de la comunidad que decidan regresar a sus territorios: la Corte precisa que el Estado tiene el deber de tomar medidas y desarrollar acciones previas que permitan a las víctimas desplazadas regresar a sus tierras tradicionales. Para que ello sea posible, las comunidades tradicionales demandan que los territorios sean "purificados" de acuerdo con rituales culturales o que se acabe el temor sobre revictimizaciones en contra de la comunidad. Por lo anterior, es deber de los Estados investigar y sancionar previamente a los responsables de los desplazamientos, y son las propias comunidades quienes deben decidir cuándo regresar. 
En este sentido, el Estado deberá tomar las medidas necesarias para garantizar su seguridad, medidas que serán diseñadas en consulta estricta con las autoridades tradicionales.

c) Fondo de desarrollo financiado por el Estado: el Estado tiene el deber de implementar programas de desarrollo que provean de servicios sociales básicos a los miembros de la comunidad cuando estos regresen, y, para ello, la creación y puesta en funcionamiento de un fondo y de un comité de seguimiento de las actividades de este permitirá avanzar si se les dota de los recursos, la infraestructura y los procedimientos adecuados consultados con los beneficiarios.

d) Disculpa pública y reconocimiento de responsabilidad internacional: como una medida de satisfacción para las víctimas y garantía de no repetición de las graves violaciones de derechos, el Estado deberá reconocer públicamente su responsabilidad internacional por los hechos sucedidos y emitir una disculpa a los miembros de la comunidad, acto que deberá llevarse a cabo con la participación de los líderes y las autoridades tradicionales y las autoridades estatales de alto nivel, debiendo ser difundido a través de los medios de comunicación nacionales.

e) Memoria: para señalar los hechos ocurridos y como recordatorio para la sociedad de lo que sucedió y no deberá repetirse en el futuro, los Estados deberán desarrollar actividades materiales y/o de otro tipo (por ejemplo, construir un monumento cuyo diseño y ubicación deberán decidirse en consulta con los representantes de las víctimas) a efectos de resaltar y reparar la memoria de las víctimas.

No debemos olvidar que la CIDH, ya desde la Sentencia de 31 de agosto de 2001, Caso de la Comunidad Mayagna (Sumo) Awas Tingni vs. Nicaragua, indicó que los usos y costumbres de los pueblos indígenas deben ser tenidos en cuenta a efectos de indemnizar, reparar y reconocer los derechos de sociedades tradicionales a las que el Estado y los particulares han desconocido sus derechos; por ello, como producto de la costumbre, la posesión de la tierra debería bastar para que las comunidades indígenas que carezcan de un título real sobre la propiedad de la tierra obtengan el reconocimiento oficial de dicha propiedad y el consiguiente registro, así como efectivamente delimitados y demarcados por el Estado, para que no persista el clima de incertidumbre permanente en el que viven los pobladores de comunidades étnicas que ven afectados 
sus derechos territoriales, sus bosques, sus aguas y demás elementos ambientales por terceros y por el mismo Estado.

En el caso del derecho a la garantía de no repetición, es de vital importancia el papel de los pueblos, las comunidades y los movimientos y organizaciones populares, cívicos y comunitarios para demandar ante los Estados, la comunidad internacional y las empresas y particulares por el deber directo de los Estados de prevenir y combatir la impunidad ambiental, al no investigar, perseguir, capturar, enjuiciar y condenar a los grandes responsables del deterioro ambiental, en particular, empresas nacionales y transnacionales o particulares con gran poder al interior de los Estados, y quienes tratan por diversos medios de eludir o evadir su responsabilidad ambiental en términos de prevenir el daño o el deterioro ambiental cuando desarrollan proyectos, obras o actividades en territorios de pueblos y sociedades tradicionales y terminan siendo violadores sistemáticos de los derechos de estas víctimas de la conflictividad ambiental.

Por otro lado, la práctica de estados, empresas y algún sector de la academia de adjudicar a la naturaleza, a los pobres y a la sobrepoblación la responsabilidad por los problemas ambientales sirve para mantener un estado de cosas que no quiere identificar a los realmente responsables de la depredación y la contaminación, hecho que revictimiza a quienes sufren las consecuencias del deterioro y el daño ambiental, en los últimos tiempos asociados al cambio climático por destrucción de los bosques y demás elementos del ambiente y a la incorporación exagerada de sustancias contaminantes a la atmósfera cuyo efecto invernadero impide al ambiente en general y al aire en particular regenerarse por sí mismos.

La respuesta inmediata desde el punto de vista jurídico para la no repetición de crímenes ambientales pasa por hacer cumplir los mandatos de los principios ambientales y las normas globales, internacionales y nacionales ya escritas, y, a renglón seguido, discutir y actualizar los estándares ambientales a mayores exigencias que limiten, reduzcan o eliminen la generación de depredación, deterioro y contaminación, especialmente en procesos y territorios que son los mayores productores netos de tal contaminación (independiente de que la hagan en sus territorios nacionales o recurran a “exportar” la generación de esta o sus residuos a terceros países ${ }^{41}$ ), los países más

\footnotetext{
${ }^{41}$ Seguramente y como resultado de lo propuesto por el controvertido escrito de SUMMERS, Lawrence, "Memorando", En: George, S. y Sabelli, F., La religión del crédito. El Banco Mundial y su imperio secular, pp. 127-143, en los últimos años es una práctica común la exportación de la contaminación y los residuos y desechos tóxicos y peligrosos a los países del Sur, y, junto con la práctica de las
} 
industrializados y aquellos que están en la carrera por alcanzarlos y sobrepasarlos, que no hacen mucho por asumir sus obligaciones jurídicas internacionales disminuyendo sus emisiones y compensando a las víctimas de sus acciones insostenibles.

La garantía de no repetición debería avanzar en la protección efectiva de los derechos ambientales, pero el persistente deterioro del ambiente y la producción y exportación exageradas de contaminación generan más deudas climáticas y ambientales por la apropiación ilegal e injustificada de los sumideros de carbono (especialmente bosques, mares y atmósfera), lo que se complementa negativamente con el discurso del mercado de "derechos de contaminación", bonos de $\mathrm{CO}_{2}$ y mecanismos de producción poco limpia como fachada de la insostenibilidad ambiental, cuyas consecuencias las sufren principalmente las sociedades y comunidades tradicionales y locales, que no tienen la capacidad de afrontar un cambio climático que no han generado.

Está reconocido ampliamente en las discusiones globales sobre ambiente y desarrollo el papel de las sociedades locales y tradicionales en el cuidado y la conservación del ambiente local, nacional y global, pues sus prácticas históricas permiten el cuidado y la conservación de los bosques naturales, pero, a su vez, no son compensadas, restituidas ni mitigadas en sus afectaciones, sino que, al contrario, deben soportar sus consecuencias, incluyendo los desplazamientos forzados ambientales, que violan tratados internacionales de derechos individuales, colectivos y ambientales ${ }^{42}$.

Naciones Unidas ha insistido en que la población más vulnerable a los efectos adversos que produce el cambio climático y otras afectaciones ambientales son aquellas sociedades, pueblos y comunidades que tienen menor responsabilidad en las causas $\mathrm{u}$ origen de los problemas asociados con el cambio climático y el deterioro ambiental, pero que, a la vez, cuentan con menos herramientas para hacerles frente; todo ello es a

\footnotetext{
"maquilas", esa contaminación ya no se produce solo en el Norte industrializado, sino que también tiene lugar en los nuevos países en proceso de industrialización para tener que pagar menos salarios o evitar las restricciones ambientales que los nacionales de los países industrializados sí exigen a sus empresas y Estados.

${ }^{42}$ La Declaración de Río de Janeiro de 1992 en sus principios 20 y 22 destaca el papel preponderante que desempeñan las mujeres y las sociedades tradicionales y locales en los usos y conservación ambiental, en particular, debido a sus conocimientos y prácticas tradicionales y, por ello, los Estados deberían reconocer y apoyar debidamente su identidad, cultura e intereses y hacer posible su participación efectiva en el logro del principio de sostenibilidad. De igual manera, la Constitución Política de Colombia en su artículo $7^{\circ}$ y $8^{\circ}$ además de reconocer y proteger la diversidad étnica y cultural de la nación colombiana, establece la obligación estatal y de los particulares de proteger las riquezas naturales y culturales del país. Así mismo, la Ley 99 de 1993 (ley general ambiental) en su artículo $1^{\circ}$ numeral 10, considera que la acción para la protección y recuperación ambientales es una tarea conjunta entre el Estado, la sociedad, las empresas y las organizaciones no gubernamentales.
} 
su vez causa de injusticias ambientales que terceros deben asumir sin tener el deber de hacerlo, pero que el derecho ambiental internacional y los derechos nacionales deberían aceptar para exigir que los verdaderos responsables por el deterioro ambiental asuman las deudas y los pasivos generados y resuelvan jurídica, política y éticamente tales atentados contra la dignidad humana y ambiental.

La Asamblea General de Naciones Unidas de 15 de septiembre de 2014 aprobó el Documento Final de la reunión plenaria de alto nivel conocida como Conferencia Mundial sobre los Pueblos Indígenas, cuyo numeral 24 recuerda la responsabilidad de las empresas transnacionales y otras empresas de respetar todas las leyes y todos los principios internacionales aplicables, incluidos los Principios Rectores de las Naciones Unidas sobre las empresas y los derechos humanos, y de operar con transparencia y de manera responsable desde el punto de vista ambiental (social y ecosistémico).

Un caso concreto de derechos como garantía de no repetición fue desarrollado por la $\mathrm{CIDH}$ en la Sentencia del Caso Pueblo Saramaka vs. Surinam con miras a garantizar la no repetición de la violación de los derechos del pueblo Saramaka y de sus integrantes; las obligaciones estatales que precisó la Corte pasan, entre otras medidas, por reconocer la personalidad jurídica del pueblo y sus miembros y la propiedad colectiva sobre sus territorios. Por lo tanto, se deberán tomar por lo menos las siguientes "medidas de satisfacción y garantías de no repetición":

a) Delimitar, demarcar y otorgar títulos colectivos sobre la territorialidad Saramaka (de acuerdo con su derecho propio según sus usos y costumbres) en un plazo razonable de máximo tres años, consultándole previamente (consultas previas, efectivas y plenamente informadas) y, especialmente, evitando que terceros o el mismo Estado realicen actos que puedan afectar a la existencia, valor, uso o goce de los territorios Saramaka, y, si existen concesiones otorgadas dentro del territorio tradicional Saramaka, el Estado debe revisarlas, evaluando eventuales modificaciones con el objeto de preservar la supervivencia del pueblo Saramaka.

b) Otorgar (en un plazo razonable) a los indígenas Saramaka reconocimiento legal de su capacidad jurídica colectiva para garantizarles el ejercicio y goce pleno de su derecho a la propiedad comunal como comunidad étnica, así como el acceso a la justicia propia, según sus usos y costumbres. 
c) En cualquier caso, el Estado deberá tomar las medidas jurídico-políticas (administrativas, legislativas o de política pública, incluyendo consultas previas con consentimiento previo, libre e informado, estudios de impacto ambiental y sociocultural, audiencias públicas, evaluaciones de impactos y planes de manejo respecto de proyectos de desarrollo o inversión que afecten a la territorialidad Saramaka) a que haya lugar para eliminar o modificar las disposiciones legales que impidan la protección del derecho a la propiedad y a los recursos naturales necesarios para la pervivencia física y cultural del pueblo Saramaka y sus integrantes ${ }^{43}$.

En atención a decisiones de carácter internacional, la Corte Constitucional colombiana también reitera que los informes de la Comisión Interamericana de Derechos Humanos constituyen "otra fuente importante de derecho internacional sobre el contenido y alcance de los derechos de las víctimas de graves violaciones a los derechos humanos a la verdad, a la justicia, a la reparación, y a la no repetición”, ya que reiteran y precisan parámetros internacionales, en particular la conexión entre estos derechos y sus alcances, por ejemplo, el derecho de las víctimas a ser reparadas de manera adecuada, proporcional, integral y eficaz respecto del daño sufrido a través de la restitución íntegra o plena, pero también a través de la indemnización, de la rehabilitación, de la satisfacción de alcance colectivo y de la garantía de no repetición, dejando claro que la reparación de las víctimas por el daño ocasionado se refiere tanto a los daños materiales como a los inmateriales y que la reparación se concreta a través de medidas tanto individuales como colectivas.

Por otro lado, en desarrollo de la Convención Marco de las Naciones Unidas sobre el Cambio Climático (CMNUCC), en noviembre de 2013, en Varsovia, la comunidad internacional precisó la necesidad de establecer un mecanismo jurídico internacional para proporcionar a las poblaciones más vulnerables ${ }^{44}$ una protección adecuada frente a las pérdidas y los daños causados por fenómenos meteorológicos extremos y por

\footnotetext{
${ }^{43}$ Para que todo lo anterior sea viable, la Corte insiste en el deber estatal de adoptar las medidas legislativas, administrativas, o de otra índole, necesarias para proporcionar a los integrantes del pueblo Saramaka los recursos efectivos y adecuados contra actos que violan su derecho al uso y goce de la propiedad de conformidad con su sistema de propiedad comunal.

${ }^{44}$ Como indican RICHARDS, Julie-Ann, y BOOM, Kelly, Carbon Majors Funding. Loss and Damage, Berlín, 2014, las ganancias de las grandes empresas emisoras de contaminación proveniente de combustibles fósiles, se deben a que externalizan el costo mayor de su proceso depredador e injusto: la devastación climática y ambiental sobre los más pobres y vulnerables.
} 
fenómenos graduales como la subida del nivel del mar, entre ellos, el "Mecanismo Internacional de Varsovia para las Pérdidas y los Daños", que debió iniciarse en este 2014 y que además debería implicar un impuesto retroactivo a los grandes emisores históricos de gases generadores de efecto invernadero y la creación de fondos para la prevención ${ }^{45}$ y el control de los daños producidos por el cambio climático del poder industrial pasado, presente y futuro hasta su freno o disminución significativa.

Pero, en actitud paradójica, la comunidad internacional propone el concepto de "adaptación" al cambio climático. Desde nuestra perspectiva, consideramos que conceptos como adaptación al cambio climático o mitigación de este requieren reflexiones amplias y sistémicas que orienten, desde la perspectiva de los derechos ambientales, el nuevo derecho ambiental contemporáneo, el cual debe contener una nueva teoría del derecho, los derechos, la justicia ${ }^{46}$ y el Estado que oriente los necesarios límites y/o autorizaciones ambientales para acceder o no y de qué manera a la naturaleza o al ambiente, con especial cuidado con las sociedades tradicionales donde subsisten los bosques que permiten resolver en parte la contaminación atmosférica como sumideros de carbono.

Tal situación demanda, entonces, la necesidad de compensar a las comunidades locales y tradicionales por su contribución directa y específica a la conservación del ambiente y a la disminución de los efectos adversos del cambio climático desde prácticas basadas en la ética del cuidado y la conservación; en particular, desde los principios de responsabilidad y solidaridad ambiental con las generaciones presentes y futuras de humanos y no humanos no solo en el escenario del Estado-nación, sino incluso más allá de sus fronteras.

El reconocimiento de los derechos de las sociedades tradicionales y locales (indígenas, afrodescendientes, raizales, campesinas y urbanas marginadas) es, a la vez, el reconocimiento de su papel en la conservación y del hecho de que no deberían soportar más el daño, el deterioro y los pasivos ambientales generados por terceros. La visibilización como víctimas colectivas y su papel en la conservación requieren que las

\footnotetext{
${ }^{45}$ En todo caso, sobre los Estados recae el deber y la obligación de prevenir los atentados contra los derechos ambientales y, por ello, deben adoptar medidas concretas y eficaces tendientes a prevenir daños, impactos negativos o atropellos a la naturaleza, a las personas individualmente consideradas y a las comunidades.

${ }^{46}$ Justicia ambiental no significa tener el mayor número de normas "ambientales" del mundo, pero no cumplirlas o cumplirlas poco o nada.
} 
medidas de mitigación y compensación tengan en cuenta la responsabilidad del Estado nacional y foráneo y sus empresas nacionales y/o transnacionales, generadores de los daños y pasivos e injusticias climáticos y ambientales, desde las especificidades locales y regionales, donde las comunidades son visibilizadas como víctimas colectivas con reivindicaciones propias por los efectos específicos en cada territorio y cultura. Las consideraciones normativas y jurisprudenciales enunciadas más arriba son un buen criterio para su desarrollo, especialmente si se orientan desde una teoría alterna que conciba los derechos como derechos ambientales.

Desde nuestra perspectiva, una nueva teoría del derecho para hacer frente a los efectos negativos del deterioro ambiental debe ser integral y sistémica, es decir, que trate de integrar los diversos compartimentos estancos en los que se ha dividido el derecho, con disciplinas que no dialogan y que imponen visiones sectoriales y parciales del mundo y del sistema jurídico.

De igual manera, una nueva teoría de los derechos ${ }^{47}$ establecerá que los derechos son todos los derechos y, en todo caso, derechos ambientales, tanto de individuos como de colectivos, y lo serán, tanto los derechos ya formulados, desarrollados (y usualmente desconocidos por Estados, empresas y particulares), ya sean derechos humanos civiles y políticos o derechos humanos económicos, sociales, culturales, colectivos y ambientales (DHESCCA), donde el tema del tiempo es sustantivo para reconocer no solo la consagración normativa de estos, sino también las múltiples dimensiones temporales en las que se sucede su negación, la reivindicación del derecho, su consagración normativa nacional o internacional, su protección o desprotección y nuevas reivindicaciones para la protección material y efectiva de tales derechos. De la misma manera, cabe señalar que los derechos no son solo de una clase de sujetos humanos (los propietarios del

\footnotetext{
${ }^{47}$ Desde una perspectiva de derechos, incluyendo los derechos colectivos y ambientales, se ha indicado un nuevo discurso fruto de acciones jurídico-políticas que precisan un derecho igual/equitativo a los sumideros de carbono (los bosques, los océanos, la atmósfera) y el establecimiento de unos límites razonables, adecuados, permisibles o sostenibles, denominado 'imperativo ambiental', como el límite a los consumos o a la huella ambiental, imperativo que tiene que ver con hasta cuánto estamos autorizados a sacar (extraer) del ambiente o a incorporar a él (desechar) después de haber consumido lo necesario para nuestro desarrollo como cultura. Tal fórmula precisa la necesidad de ser discutida pública y políticamente y acordada entre todos los sujetos de derecho para indicar cuál es ese límite, el cual no podrá ser superado si efectivamente se considera necesario para la supervivencia humana presente y futura sobre la ecosfera. Para un debate más amplio sobre el imperativo ambiental, véase MESA CUADROS, Op. cit., 2013. pp. 268 a 282.
} 
capital y la empresa), sino también de todos los seres humanos presentes y futuros, así como de los no humanos presentes y futuros.

Igualmente, una nueva teoría del Estado debería contener las previsiones necesarias desde escenarios en los cuales sean viables y materializables los derechos y su protección efectiva, ya que creemos que el Estado social de derecho es insuficiente para la protección de todos los derechos y, seguramente, el Estado ambiental de derecho podría tener en germen los mecanismos, principios y derechos de la sociedad global del tiempo actual y futuro, para que la dignidad humana y no humana (cultural y ecosistémica) sea el escenario de materialización de los derechos de todas y de todos los sujetos, donde el comercio justo, la producción limpia, la democracia local y global y la información ambiental con sentido público orienten la idea de sostenibilidad ambiental, más allá del discurso del "desarrollo sostenible" o la "economía verde", recuperando y defendiendo la poca institucionalidad ambiental (en sentido estricto) que subsiste.

Por último, una nueva teoría de la justicia deberá ser, por todas las consideraciones anteriores, una teoría de la justicia ambiental ${ }^{48}$, la cual debe considerar por lo menos tres dimensiones clave para su concreción: el carácter del sujeto, en el sentido de que sean sujetos de derechos no solo unos cuantos humanos, sino todos los humanos y los no humanos; el carácter de la temporalidad, los derechos son de los humanos y no humanos presentes y futuros; y el carácter de la territorialidad o espacialidad en un nuevo escenario, el global o cosmopolita, en el cual se protegen todos los derechos, es decir, más allá de los límites estrechos del Estado-nación, convertido desde hace varias décadas en el escenario de la discriminación y la negación de los derechos de quienes no son sus nacionales o no tienen o no pueden.

En tal sentido, la justicia ambiental ${ }^{49}$ en la era del cambio climático antropogénico deberá reconocer los derechos ambientales de los desplazados ambientales (empezando

\footnotetext{
${ }^{48}$ La ausencia de justicia ambiental implica la persistencia de la injusticia la cual dificulta el reconocimiento de los daños e impactos ambientales negativos (incluidos los pasivos ambientales) y la nueva división del trabajo internacional propicia nuevos daños ambientales, ya que las actuaciones estatales antiambientales limitan el cumplimiento del deber constitucional de proteger el derecho al ambiente sano usualmente promovido por el papel negativo que juegan empresas nacionales y extranjeras, las cuales, con el discurso de la "responsabilidad social empresarial" (RSE), promueven mayores impactos transfronterizos no reconocidos que considerados pasivos ambientales, perpetúan a su vez la injustica climática y ambiental global, la cual a su vez afecta mayoritariamente a pueblos y comunidades tradicionales y locales vulnerables.

${ }^{49}$ Cuando AGARWAL, Anil y NARAIN, Sunita, Global Warming in an unequal world: a case of environmental colonialism, Centre for Science and Environment, Delhi, 1991, formularon la propuesta sobre un "derecho igual a los sumideros de carbono" (bosques y océanos) que implicaba restricciones al
} 
por las sociedades y pueblos tradicionales rurales y agrarios) por las conductas de sujetos específicos depredadores, contaminadores y que se apropian injustamente del ambiente y sus elementos. Tales derechos lo serán en una democracia ambiental ${ }^{50}$ en la que todos los seres tengan derecho al acceso equitativo a los elementos del ambiente, comenzando por aquellos pueblos y sociedades que usan la naturaleza de manera adecuada, en particular los elementos de la naturaleza para garantizar sus consumos endosomáticos para satisfacer sus necesidades básicas ${ }^{51}$, es decir, algunos habitantes y propietarios colectivos de los pocos bosques naturales que quedan en la ecosfera.

\title{
IV. A MANERA DE CONCLUSIONES
}

La sociedad civil, los pueblos, sociedades y comunidades tradicionales y locales, unos movimientos ambientalistas consecuentes y unas políticas públicas ambientales desde el

\begin{abstract}
ejercicio de actividades contaminantes, especialmente aquellas que contribuían mayoritariamente con la incorporación de gases a la atmósfera generadores del efecto invernadero y causa central de los cambios climáticos asociados a incrementos sustanciales en la temperatura del globo, no intuían la manera como el capital ha optado por la vía de la aceptación del principio "el que contamina paga" como la autorización para la contaminación en lugar de evitarla o prevenirla, y, por ello, este "antiprincipio" es la base central de las prácticas económicas del último tiempo en que las empresas nacionales y transnacionales se "tiñen" de verde para aparecer como capitalistas con rostro ecologista, si bien se ha probado y demostrado que no lo son, pues su discurso "verde" es desvirtuado una vez que se analizan sus prácticas depredadoras y contaminadoras consecuentes con su propuesta de apropiación privatística ilimitada, aun a costa de los derechos de propiedad colectiva, común o comunitaria de sociedades tradicionales, étnicas y campesinas. En cualquier caso, es necesario indicar que el derecho igual a los sumideros de carbono debería actualizarse y reformularse bajo criterios de equidad ambiental.
\end{abstract}

${ }^{50}$ En MESA CUADROS, Op. cit., 2013, pp. 389 y ss., precisamos los elementos centrales de la democracia ambiental (todos los sujetos humanos y no humanos, presentes y futuros son ciudadanos ambientales más allá de los límites estrechos del Estado-nación). Por su parte, SHIVA, Vandana, Manifiesto para una democracia de la tierra. Justicia, sostenibilidad y paz, Paidós, Barcelona, 2005, ha enunciado, además, una serie de principios que permiten reconocer lo que ella denomina "Democracia de la Tierra": principio de valor intrínseco de todas las especies, pueblos y culturas; principio de comunidad de la Tierra como democracia de toda la vida en su conjunto; principio de defensa de la diversidad natural y cultural; principio de sustento como derecho natural de todos los seres; principio de economías vivas locales; principio de democracia viva y económica; principio de culturas vivas que nutren la vida; y principio de democracia global, paz, atención y compasión.

\footnotetext{
${ }^{51}$ El uso de la naturaleza basado en el 'control vertical de los pisos térmicos' como estrategia adaptativa de sociedades tradicionales andinas ha permitido la pervivencia de bosques naturales que, junto con huellas ambientales sostenibles (basadas en usos adecuados orientados por el ayuno y los consumos endosomáticos solo para satisfacer necesidades básicas y no la acumulación y el deterioro), posibilitan la contribución significativa de las sociedades tradicionales a la conservación y a evitar el deterioro ambiental, especialmente al limitar los efectos adversos del cambio climático y el efecto invernadero, conservando los bosques naturales, es decir, en el caso colombiano y otros países latinoamericanos, donde hay bosques naturales conservados y cuidados hay sociedades tradicionales; en últimas, es la existencia de tales pueblos y sociedades quienes garantizan la pervivencia de los bosques naturales . Para un debate más amplio sobre uso y control vertical de pisos térmicos, véase, OSBORN, Ann. Las cuatro estaciones. Mitología y estructura social entre los U’wa. Bogotá: Banco de la República - Museo del Oro, 1995.
} 
ambientalismo popular podrían orientar algunos de los elementos jurídico-políticos y éticos para un plan de compensación de los daños causados por el cambio climático provocado por el capital y las empresas de la economía hegemónica global contra las sociedades tradicionales y locales.

El Derecho ambiental y la academia tienen muchos retos a la hora de formular propuestas alternativas al quehacer convencional de Estados, empresas, capital y mercado. Seguramente una justicia ambiental y una jurisdicción ambiental en sentido estricto ayudarían a construir condiciones de posibilidad material para afrontar los retos del deterioro ambiental y sus afectaciones a los derechos. Para ello, se requieren nuevas visiones ambientales sobre el derecho, los derechos, la justicia y el Estado que orienten la producción de las normas, su interpretación por los jueces y el debate jurídico crítico de una doctrina jurídica nacional e internacional basada en criterios, principios y derechos ambientales.

Reiteramos el deber estatal y de las empresas de no "someter" a los programas de adaptación al cambio climático a las sociedades tradicionales y sí precisar desde una agenda global ambiental consistente las responsabilidades ambientales diferenciadas que los depredadores y contaminadores del Norte y Sur industrializado han generado sobre sociedades tradicionales y agrarias y urbanas marginadas, así como los tiempos específicos en que la comunidad internacional y las Naciones Unidas deban asumir con rigor este deber jurídico, político y ético de responsabilidad ambiental con las actuales y futuras generaciones.

En cualquier caso, cabe insistir en que las víctimas del desplazamiento ambiental no tienen por qué sufrir revictimización, sino que deberían ser compensadas, y en que habría que formular y aclarar jurídicamente las nuevas formas de verdad, justicia, reparación y garantía de no repetición, bajo estándares ambientales internacionales y comunitarios exigentes, lo que es un imperativo ético, político y jurídico actual; de la misma manera, la información ambiental, que es de interés público según la ley nacional colombiana, no debería ser apropiada privatísticamente por grandes empresas de los transgénicos, los insumos agrícolas y las farmacéuticas, las dueñas de proyectos de infraestructura, que tratan de cerrar el círculo de los agronegocios de la vida y la muerte. En cualquier caso, la soberanía, seguridad y autonomía alimentarias presentes y futuras dependen de si tomamos partido por el bien común o por la mercantilización generalizada de la naturaleza. 
Para el caso colombiano, la influencia del conflicto armado interno ha jugado un papel de primer orden para el deterioro, la depredación y la contaminación ambiental, donde agentes nacionales e internacionales presionan a sectores regionales y locales en nuestro país para promover la guerra como negocio y desplazan a pueblos, sociedades, comunidades e individuos para poder asentar sus propuestas de maldesarrollo, desterritorializando y reterritorializando amplios ecosistemas para "someterlos" junto con sus habitantes a los nuevos mandatos del extractivismo interno y global.

Por ello, es importante tener en cuenta las condiciones materiales en momentos de la historia ambiental del mundo que han demostrado que la naturaleza es depredada y contaminada no solo en períodos de conflictos armados y guerras (incluso es usada como un instrumento de guerra), sino que, en períodos de paz, las extracciones, intercambios, consumos, contaminaciones y desechos se incrementan sustantivamente, supuestamente para garantizar la paz social; es decir, de nuevo se gestan las bases de nuevos conflictos que, a su vez, afectan a las poblaciones pobres y más vulnerables al deterioro ambiental.

Por todo lo anterior, el tema central no debería ser la "adaptación al cambio climático", sino "cómo evitar en la medida de lo posible o prevenir el cambio climático"; en últimas, los "desadaptados" del cambio climático son los depredadores y contaminadores del ambiente global, internacional, nacional, regional y local (Estados, empresas nacionales y transnacionales) y sus agentes de pensamiento y acción política no ambiental, y no las sociedades tradicionales rurales agrarias y urbanas que viven y sobreviven con consumos endosomáticos sostenibles a partir de prácticas concretas de acceso, uso, apropiación, producción, redistribución, retribución, compensación, mitigación, reproducción, consumo y conservación de bienes naturales y ambientales (elementos y componentes del ambiente en el cual viven y construyen cultura) en una perspectiva de dignidad a partir del reconocimiento de la integralidad y complejidad ambientales, más allá de las formas hegemónicas depredadoras y contaminadoras globalizadas inadecuadamente.

La idea de justicia ambiental tiene en algunas normas nacionales y otras internacionales, así como en decisiones de tribunales estatales y en los sistemas interamericano, interafricano o europeo, elementos para el acceso a la justicia. Las definiciones básicas sobre derechos individuales civiles y políticos, ampliados a los derechos económicos, sociales y culturales, colectivos y ambientales, desde una visión sistémica e integral, 
ayudarían a concretar la justicia material desde la nueva teoría de los derechos ambientales a favor de sociedades tradicionales, las más vulnerables a la conflictividad ambiental y al cambio climático causado por empresas, sociedades y Estados con capacidad de daño y deterioro del ambiente y los derechos.

Las orientaciones normativas de límites a la depredación y la contaminación expresadas en los principios ambientales arriba enunciados, junto con decisiones judiciales razonables desde la perspectiva ambiental de conservación que desarrollan los contenidos concretos de la protección efectiva de derechos ambientales, contribuyen significativamente a concretar los derechos a la verdad, la justicia, la reparación y las garantías de no repetición (restitución, rehabilitación y satisfacción-indemnización desde los principios de priorización, concurrencia de las acciones de reparación, participación activa de los afectados en la toma de decisiones y principio de transformación de las circunstancias que originaron los daños o pusieron a las sociedades tradicionales en vulnerabilidad) contra pueblos y sociedades tradicionales, cuestión en la que la academia juega un papel relevante para encontrar respuestas a casos específicos.

\section{BIBLIOGRAFÍA}

AGARWAL, Anil y NARAIN, Sunita, Global Warming in an unequal world: a case of environmental colonialism, Centre for Science and Environment, Delhi, 1991.

AGUILERA KLINK, Federico, "La tragedia de los comunes o la tragedia de la malinterpretación en economía", Agricultura y sociedad, 61, octubre-diciembre de 1991, Madrid, pp. 157-181.

ANGEL MAYA, Augusto, El retorno de Ícaro. La razón de la vida. Muerte y vida de la filosofía. Una propuesta ambiental, Asocars, IDEA, PNUMA, PNUD, Bogotá, 1997.

BID, “Agricultura y Clima Futuro en América Latina y el Caribe: Impactos Sistémicos y Posibles Respuestas”, documento de debate núm. IDB-DP-329, febrero de 2014.

CHHATRE, Ashwini y AGRAWAL, Arun, Trade-offs and synergies between carbon storage and livelihood benefits from forest commons, PNAS, 20 de octubre de 2009, vol. 106, núm. 42, pp. 17667-17670 (www.pnas.orgcgidoi10.1073pnas.0905308106). 
CORTE CONSTITUCIONAL DE COLOMBIA, Sentencia C-715 de 2012. Derechos de las víctimas del conflicto armado interno, MP: Luis Ernesto Vargas Silva.

- Sentencia T-135/2013. Derechos de campesinos ribereños en el proyecto hidroeléctrico El Quimbo, MP: Jorge Iván Palacio.

CORTE INTERAMERICANA DE DERECHOS HUMANOS (CIDH), Caso Pueblo Saramaka vs. Surinam. (Excepciones preliminares, fondo, reparaciones y costas). Sentencia de 28 de noviembre de 2007, Serie C núm. 172.

- Caso Comunidad Indígena Sawhoyamaxa vs. Paraguay. (Fondo, reparaciones y costas). Sentencia de 29 de marzo de 2006, Serie C núm. 146.

- Caso Comunidad Indígena Yakye Axa vs. Paraguay. (Interpretación de la Sentencia de Fondo, reparaciones y costas). Sentencia de 6 de febrero de 2006, Serie C núm. 142.

- Caso Comunidad Indígena Yakye Axa vs. Paraguay. (Fondo, reparaciones y costas). Sentencia de 17 de junio de 2005, Serie C núm. 125.

- Caso Comunidad Mayagna (Sumo) Awas Tigni vs. Nicaragua. (Fondo, reparaciones y costas). Sentencia de 31 de agosto de 2001, Serie C núm. 79.

DALY, Herman E., "Criterios operativos para el desarrollo sostenible”, Debats, 35-36, 1991, pp. 39-41.

EJOLT - ENVIRONMENTAL JUSTICE ORGANIZATIONS, LIABILITIES AND TRADE, Atlas global de justicia ambiental, Instituto de Ciencias y Tecnología Ambientales - UAB, Barcelona, 2014 (http://ejatlas.org/).

FUNK, Mackensie, Windfall. The Booming Business of Global Warming, Penguin Press, Nueva York, 2014.

GARCÍA VEGA, Miguel Ángel, "Quién hace caja con el cambio climático”, El País, 24 de febrero de 2014, Madrid. Recuperado el 25 de febrero de 2014, de http://sociedad.elpais.com/sociedad/2014/02/21/actualidad/1393012503_128290.html.

GUDYNAS, Eduardo, El mandato ecológico. Derechos de la Naturaleza y políticas ambientales en la nueva Constitución, Abya Yala, Quito, 2009.

HARDIN, Garret, "Tragedy of the Commons", Science, vol. 162, núm. 3859, 13 de diciembre de 1968, pp. 1243-1248. 
JAQUENOD DE ZSÖGÖN, Silvia, El Derecho ambiental y sus principios rectores, Dykinson, Madrid, 1991.

LEFF, Enrique, Aventuras de la Epistemología Ambiental: de la articulación de ciencias al diálogo de saberes, Siglo XXI, México, 2006.

LOCKE, John, Segundo tratado sobre el gobierno civil, Alianza, Madrid, 2000.

MARTÍNEZ ALIER, Joan, De la economía ecológica al ecologismo popular, Icaria, Barcelona, 1994.

MESA CUADROS, Gregorio, Derechos ambientales en perspectiva de integralidad: concepto y fundamentación de nuevas demandas y resistencias actuales hacia el Estado ambiental de derecho, Universidad Nacional de Colombia, Bogotá, 2013.

— "De la ética del consumo a la ética del cuidado: de cómo otro mundo sí es posible desde otra manera de producir y consumir", Revista Pensamiento Jurídico, núm. 22, mayo-agosto de 2008, Antropología, Derecho y Política, Facultad de Derecho, Ciencias Políticas y Sociales de la Universidad Nacional de Colombia, Bogotá, pp. 333 a 345.

_ "Principios ambientales como reglas de organización para el cuidado, la vida, la conservación y el futuro". En: Debates ambientales contemporáneos. (Editor) Bogotá: Editorial Unijus Facultad de Derecho, Ciencias Políticas y Sociales de la Universidad Nacional de Colombia, 2010, pp. 17 a 74.

- "Deuda ambiental y climática: amigos o depredadores-contaminadores del ambiente", Revista Pensamiento Jurídico, núm. 25, mayo-agosto de 2009, Facultad de Derecho, Ciencias Políticas y Sociales de la Universidad Nacional de Colombia, Bogotá, pp. 77 a 90.

— "Resistencias en el contexto de la globalización económica y política", Tolosa, W., Mesa Cuadros, G. y Bello, M. (eds.), La resistencia civil: estrategias de acción y protección en los contextos de guerra y globalización, Memorias Encuentro Internacional, Planeta Paz, ATI, PIUPC de la Universidad Nacional de Colombia, Bogotá, 2004.

- Ambiente y derechos: tendencias actuales en ética, politica y derechos ambientales, tesina de doctorado, Universidad Carlos III, Madrid, 2001.

MOLNAR, Augusta. 2013. ¿Propietarios o trabajadores sin tierras? El mundo en transición, Ponencia presentada en La Iniciativa para los Derechos y Recursos, $14^{\circ}$ 
Diálogo sobre Bosques, Gobernanza, y Cambio Climático. Bogotá, Colombia, 21 de marzo 2013.

NACIONES UNIDAS, COMITÉ DE DERECHOS ECONÓMICOS, SOCIALES Y CULTURALES, Observación General núm. 7, Aplicación del Pacto Internacional de Derechos Económicos, Sociales y Culturales - PIDESC. El derecho a una vivienda adecuada (párrafo 1 del artículo 11 del Pacto): los desalojos forzosos (16. ${ }^{\circ}$ período de sesiones, 1997), UN Doc. E/1999/22, anexo IV, 1997.

NACIONES UNIDAS, Conferencia de las Naciones Unidas sobre el Cambio Climático, COP19, Varsovia, 2013.

- Declaración de las Naciones Unidas sobre Derechos de los Pueblos Indígenas, A/RES/61/295, 2007.

NADAL, Alejandro, "El arca de Noé se hunde en el mercado financiero", La Jornada, 12 de marzo de 2014, México. Recuperado el 13 de marzo de 2014, de: http://www.jornada.unam.mx/2014/03/12/opinion/026a1eco.

ORGANIZACIÓN DE LOS ESTADOS AMERICANOS (OEA), Convención Americana sobre Derechos Humanos, San José de Costa Rica, 1969.

ORGANIZACIÓN INTERNACIONAL DEL TRABAJO (OIT), Convenio 169 sobre pueblos indígenas y tribales en países independientes, OIT, Ginebra, 1989.

OSBORN, Ann. Las cuatro estaciones. Mitología y estructura social entre los U'wa. Bogotá: Banco de la República - Museo del Oro, 1995.

POLANYI, Karl, La gran transformación. Crítica del liberalismo económico, La Piqueta, Madrid, 1944.

PHILIPPOPOULOS-MIHALOPOULOS, Andreas (ed.), Law and Ecology: New Environmental Foundations, Routledge, Bristol, 2011.

PROCURADURÍA GENERAL DE LA NACIÓN, Primero las víctimas: criterios para la reparación integral de los grupos étnicos, PGN, Bogotá, 2008.

REES, William E., "Indicadores territoriales de sostenibilidad”, Ecología Política, 12, 1996, pp. 27-42. 
REVISTA MUNDO VERDE, "Refugiados ambientales suman 114 millones", México. Recuperado el 24 de mayo de 2014, de: http://www.revistamundoverde.net/noticiasambientales/refugiados-ambientales-suman-114-millones.

RICHARDS, Julie-Ann y BOOM, Kelly, Carbon Majors Funding. Loss and Damage, Berlín, 2014.

RODRÍGUEZ GARAVITO, César, MORRIS, Meghan, ORDUZ, Natalia y BURITICÁ, Paula, La consulta previa a pueblos indígenas: los estándares del derecho internacional, Uniandes, Bogotá, 2010.

RUDAS LLERAS, Guillermo, "Minería, medio ambiente y cambio climático: una señal de alarma", Razón Pública, 2011, edición digital (http://www.razonpublica.com/index.php/econom-y-sociedad-temas-29/1697.html).

SANTOS, Boaventura de Souza, Refundación del Estado en América Latina. Perspectivas desde una epistemología del Sur, Siglo del Hombre, UAndes, Siglo XXI, Bogotá, 2010.

SHIVA, Vandana, Manifiesto para una democracia de la tierra. Justicia, sostenibilidad y paz, Paidós, Barcelona, 2005.

SUMMERS, Lawrence, "Memorando", En: George, S. y Sabelli, F., La religión del crédito. El Banco Mundial y su imperio secular, Intermón, Barcelona, 1996, pp. 127143.

WACKERNAGEL, Mathis, "Advacing sustainable resource management: using ecological footprint analysis for problem formulation, policy development, and communication". Prepared for DG Environment, European Commission Project officers, Marc Vanheukelen, Otto Linher, 2001, p. 20 [Recurso electrónico UC3M].

- “¿Ciudades sostenibles?”, Ecología Politica, 12, 1996, pp. 43-50.

WACKERNAGEL, Mathis y REES, William, Nuestra huella ecológica. Reduciendo el impacto humano sobre la tierra, Instituto de Ecología Política - LOM eds., Santiago de Chile, 2001.

ZETTER, Robert, "Proteger a los desplazados por razones ambientales: desarrollar la capacidad de los marcos jurídicos y normativos", Diálogo Alto Comisionado del ACNUR, Ginebra, 2010. 